ERC Working Papers in Economics 12/04

April 2012

\title{
The Formal/Informal Employment Earnings Gap: Evidence From Turkey
}

\author{
Aysit Tansel \\ Department of Economics \\ Middle East Technical University \\ Ankara 06800 Turkey \\ Email: atansel@metu.edu.tr \\ Tel: 0090(312)210 2057 Fax:0090(312)210 7964 \\ Institute for the Study of Labor (IZA) Bonn, Germany \\ and \\ Economic Research Forum (ERF) Cairo, Egypt \\ Elif Oznur Kan \\ Department of Economics \\ Cankaya University, Ankara, Turkey \\ E-mail: elifoznurkan@ cankaya.edu.tr \\ Telephone: 90.312.233 1208 \\ Fax: 90.312.233 1027
}




\title{
THE FORMAL/INFORMAL EMPLOYMENT EARNINGS GAP: EVIDENCE FROM TURKEY ${ }^{1}$
}

\author{
Aysit Tansel \\ Department of Economics \\ Middle East Technical University, Ankara, Turkey \\ E-mail: atansel@metu.edu.tr \\ Telephone: 90.312.210 2057 \\ Fax : 90.312.210 7964 \\ and \\ Institute for the Study of Labor (IZA) Bonn, Germany and \\ Economic Research Forum (ERF) Cairo, Egypt \\ and \\ Elif Oznur Kan \\ Department of International Trade \\ Cankaya University, Ankara, Turkey \\ E-mail: elifoznurkan@cankaya.edu.tr \\ Telephone: 90.312 .2331208 \\ Fax: 90.312.233 1027
}

April, 2012

\footnotetext{
${ }^{1}$ This paper is based on Elif Oznur Kan's PhD thesis (see Kan, 2011) prepared under the supervision of Aysit Tansel at the Department of Economics, METU. Elif Oznur Kan would like to thank Hakan Ercan, Tolga Omay and Ozan Acar for helpful comments on her PhD thesis. Thanks are also due to Murat Karakas, Responsible of Labour Force and Living Conditions Group at the Turkish Statistical Institute for his kind help in implementing this study. Any errors are our own.
} 


\begin{abstract}
In this study, we examine the formal/informal sector earnings differentials in the Turkish labor market using detailed econometric methodologies and a novel panel data set drawn from the 2006-2009 Income and Living Conditions Survey (SILC). In particular, we test if there is evidence of traditional segmented labor markets theory which postulates that informal workers are typically subject to lower remuneration than similar workers in the formal sector. Estimation of standard Mincer earnings equations at the mean using OLS on a pooled sample of workers confirms the existence of an informal penalty, but also shows that almost half of this penalty can be explained by observable variables. Along wage/self-employment divide, our results are in line with the traditional theory that formal-salaried workers are paid significantly higher than their informal counterparts. Confirming the heterogeneity within informal employment, we find that self-employed are often subject to lower remuneration compared to those who are salaried. Moreover, using quantile regression estimations, we show that pay differentials are not uniform along the earnings distribution. More specifically, we find that informal penalty decreases with the earnings level, implying a heterogeneous informal sector with upper-tier jobs carrying a significant premium and lower-tier jobs being largely penalized. Finally, fixed effects estimation of the earnings gap depict that unobserved individual fixed effects when combined with controls for observable individual and employment characteristics explain the pay differentials between formal and informal employment entirely, thereby implying that formal/informal segmentation may not be a stylized fact of the Turkish labor market as previously thought.
\end{abstract}

Keywords: Earnings gap; formal/informal employment; labor market dynamics; panel data; Turkey.

JEL Classicification: J21, J31, J40, O17 


\section{INTRODUCTION}

Informal employment has traditionally been associated with inferior earnings, wage inequality and resulting poverty in the mainstream literature. The conventional segmented markets theory explains this stylized fact by postulating that labor informality is nothing but a survivalist alternative for those disadvantaged or rationed out of formal employment opportunities (Fields, 1975; Mazumdar, 1976; Bernabe, 2002; Perry et al., 2007). Therefore, in a segmented labor market informal workers are typically subject to lower remuneration than similar workers in the formal sector, where wages are set above market clearing prices for institutional or efficiencywage reasons (Günther and Launov, 2006:2). On the other hand, competitive labor markets theory argues that informal employment may equally well be voluntary based on private cost-benefit calculations of individuals and firms (Magnac, 1991; Pradhan and van Soest, 1995; Cohen and House, 1996; Marcoullier et al., 1997; Maloney, 1999; Saavedra and Chong, 1999; Gong and van Soest, 2002: quoting Henley et al., 2009:1). In such a competitive market framework, formal/informal pay inequalities tend to disappear, especially when compensating differentials are accounted for. In contrast to these two polar views, a third view originated by Fields (1990), posits a heterogeneous informal sector consisting of an upper-tier of those who are voluntarily informal; and a lower-tier of those who cannot afford to be unemployed but have no hope for a formal job (Cunningham and Maloney 2001; Fields 1990, 2005; Henley et al., 2009). In such a setting, the commonly accepted assumption is that the upper-tier often corresponds to selfemployment, whereas the lower-tier segment consists mostly of informal wage workers. In this study, we aim to discuss the relevance of these theories to the Turkish labor market.

There is an ample literature which purports to test the theory using estimation of formal/informal earnings gap. As put by Nguyen et al. (2011:2): “Embedded in revealed preferences principle, and considering income as a proxy of individual utility, the approach assumes that if informal workers earn more than their formal counterparts (controlling for observed and unobserved characteristics), one could have good presumptions that they have deliberately chosen the informal sector". However, as with the theory, empirical evidence to date also seems to be mixed and inconclusive. Confirming the traditional segmented labor markets theory, most early studies find that formal sector workers are better rewarded for their earning-relevant characteristics than their informal sector counterparts (see Mazumdar, 1981; Heckman and Hotz, 1986; Roberts, 1989; Pradhan and Van Soest, 1995; Tansel, 1999, 2000; Gong and Van Soest, 2002). In contrast, several recent studies report that wage differentials between formal and informal sector may not 
be a stylized fact. For example, Pratap and Quintin (2006) find no difference between formal and informal earnings in Argentina after controlling semiparametrically for individual and employer characteristics. Also, Tannuri-Pianto and Pianto (2002) show that at high quantiles of the earnings distribution, differences in returns to skills completely disappears in the Brazilian labor market.

In this study, we aim to complement the existing literature by examining the earnings performance of formal and informal workers in Turkey. Turkey, given its demographic and economic dynamics, provides rich evidence for a large and heterogeneous informal labor market. A comprehensive diagnosis of pay differentials, its underlying factors and detailed decompositions across individual and job characteristics are of great importance in such a developing country context. First and foremost, informal labor accounts for a substantial share of both urban and rural employment in most developing countries. ${ }^{1}$ According to the Turkish Statistical Institute (TurkStat), the share of informal employment in the Turkish labor market stands high at 38.4 percent as of January 2012 (TurkStat, 2012). Moreover, TurkStat reports that the rate of informality to be 82.8 for the agricultural employment and 25.8 percent for the nonagricultural employment. Evidently, an improved understanding of the formal/informal pay gap is crucial for addressing its welfare, equity and poverty consequences. Second, earnings gap is commonly used to test for the existence of segmented versus competitive labor markets. Large differentials are often viewed as an evidence for institutional rigidities in the labor markets, thereby suggesting need for policy action considering equity and efficiency purposes. Third, disentangling the dynamics of formal/informal pay gap across wage- versus self-employment workers and along various quantiles of the earnings distribution enables a multidimensional array of policy implications. In this fashion, one can also address the issue of heterogeneity within formal and informal sectors which is often an important issue in such earnings analyses.

Against this background, we aim to contribute to the literature by employing a rich panel data set and recently developed econometric methodologies to explore following research questions: (1) Is there a formal-informal employment earnings gap in Turkey? (2) Is there an informal sector earnings penalty that indicates the presence of segmentation in the Turkish labor market? (3) How does the earnings distribution across formal/informal sectors alter when employment is further broken down into wage-employment and self-employment, i.e. formal wage workers, formal selfemployed, informal wage workers, informal self-employed? (4) What are the main individual,

\footnotetext{
${ }^{1}$ According to the International Labor Organization (ILO), informal employment accounts for one-half to three-quarters of nonagricultural employment in the developing countries: 48 percent in North Africa, 51 percent in Latin America, 65 percent in Asia, and 72 percent in Sub-Saharan Africa (ILO, 2002b)
} 
household and employment type characteristics driving the formal-informal employment earnings gap? (5) To what extent can earnings differentials be explained by such observable characteristics and unobserved time-invariant individual heterogeneity?

The empirical analysis is based on micro level panel data from the TurkStat Income and Living Conditions Survey (SILC) for 2006-2009 period. Subsuming a rich set of information on household expenditure, income and assets, employment and living conditions, SILC is invaluable for implementing a comprehensive formal/informal earnings gap analysis for Turkey. Of particular interest for this study are the income and labor market variables, such as employment type, registration to the social security institution and earnings. The data set also includes several other variables of personal, household and job characteristics such as age, gender, education, household head status, household type, marital status, work experience, sector of economic activity, firm size and others which are commonly used for explaining the underlying dynamics of the earnings differentials. Moreover, the questionnaire allows us to distinguish not only between the formal/informal divide based on registration to social security institution, but also across employed/non-employed status and wage/self-employed work. To the best of our knowledge, this study will be the first to use the SILC and its panel data set for analyzing formal/informal earnings gap.

The empirical analysis consists of examining the earnings differential along multiple dimensions, disentangling at formal/informal employment, wage/self-employment and mean/quantiles of the earnings distribution. For this purpose, we first estimate standard Mincer earning regressions at the mean using ordinary least squares (OLS) and control for a rich set of observable individual, household and establishment characteristics. However, as pointed out in several earlier studies, one must account for unobserved factors that are associated with the level of earnings and intrinsic heterogeneity within formal and informal sectors. To address the first one, the panel nature of our data enables us to apply fixed effects estimation, thereby account for the timeinvariant unobservables which constitute main determinants of pay differentials. For the latter, we rely on quantile regression (QR) estimation which allows for a distributional analysis of the pay gap at various points of the earnings distribution, thereby acknowledging potential structural heterogeneity within sectors.

Our results reveal several important patterns. First, OLS in levels estimation of standard Mincerin type earnings equations confirms the existence of an informal penalty, but also shows that almost 
half of this penalty can be explained by observable variables. Moreover, the unexplained informal penalty for female workers is found as twice of that for the male workers when only individual characteristics are controlled, whereas when job variables are also introduced to the model, informal penalty for women appears at parity with that for male workers. Regarding formal/informal pay differences along wage/self-employment divide, formal-salaried workers are paid significantly higher than their informal counterparts. Moreover, confirming the heterogeneity within informal employment, we find that self-employed are subject to lower remuneration compared to those who are salaried. The quantile regression results show that pay differentials are not uniform along the earnings distribution, i.e. informal penalty decreases with the earnings level. A particularly important finding is that, in contrast to the mainstream literature which views informal self-employed as the upper-tier and wage earners as the lower-tier, lower-tier informal employment rather corresponds to self-employment in the Turkish labor market. Finally, fixed effects regression results show that unobserved individual fixed effects when combined with controls for observable individual and employment characteristics explain the pay differentials between formal and informal employment entirely. The implication is quite remarkable in the sense that formal/informal segmentation may not be a stylized fact of the Turkish labor market as previously thought.

The remainder of the paper is organized as follows: Section 2 provides a brief survey of empirical literature on earnings differentials in the formal/informal labor markets. Section 3 describes the data and definition of main variables used in the study along with a brief discussion of summary statistics. The econometric methodology and models are presented in Sections 4, and results are reported in Section 5. Finally, Section 6 provides a summary of the main findings and implications for policy.

\section{SURVEY OF LITERATURE}

Carneiro and Henley (2001) consider the determinants of earnings and selection of workers into formal and informal employment, using the 1997 Brazilian household survey. In order to model selection, they adopt Lee (1978)'s three step procedure of simultaneous modeling of participation decision and earnings. Accordingly, they first estimate a reduced-form probit model of formal/informal sector participation choice and compute selectivity correction term which they later incorporate into the Mincer earning equation. In the last stage, they construct predicted earnings differentials using the earning function they estimated in stage two. The results imply 
that age, tenure, education and gender are significant determinants of earnings. Furthermore, they report that the selectivity correction term is statistically significant in the earnings equation, hence quantitatively important in modeling earnings differentials.

Gong and van Soest (2002) analyze the wage differentials between formal and informal sectors using quarterly panel data from Mexico. They use a dynamic random effects wage regression to explain the wage formation and differentials, thereby controlling for possible selection bias due to unobserved time-invariant heterogeneity which affects both wages and sector choice. The study is the first such to consider wages and sector choice to be simultaneously determined in one dynamic panel data setting. Using Heckman (1981)’s Monte Carlo simulated maximum likelihood methodology, Gong and van Soest find that age significantly affects formal sector wage, but not the informal sector wage; returns to education are positive in both sectors though much higher in the formal sector; lagged labor market state has no effect on wages and that random effects are insignificant in the wage determination process.

For the purpose of testing wage differentials across formal/informal divide in Argentina, Pratap and Quintin (2006) resort to propensity matching score matching (PSM) methodology to deal with the sample selection problem often inherent in such analyses. As with many other studies, they find a 25 percent formal wage premium using standard OLS estimation, controlling for individual and establishment characteristics. However, once they match observably similar workers using semi-parametric methods, Pratap and Quintin detect no evidence of a formal-sector wage premium; thereby reject the segmented formal/informal labor markets theory in Argentina. In particular, they employ three different matching techniques: caliper, nearest neighbor and Epanechnikov kernel. In the last section, they evaluate robustness of their analysis considering the importance of controlling for firm size, unobserved worker characteristics which may affect both selection decision and wages and the value of other pecuniary and non-pecuniary benefits of a job.

Badaoui et al. (2008) re-examine the informal sector wage penalty considering the non-selfemployed South African males. They emphasize the potential sample selection bias to be the main challenge in the context of measuring formal-informal sector wage gap. In this regard, their analysis is structured in a way that comprises several different estimations and comparison of their results. First, they run a simple ordinary least squares in levels on a standard Mincer wage equation, including only the informal sector dummy. The resulting 112 percent formal sector 
wage premium falls substantially to 53 percent, once human capital variables (i.e. gender, race, marital status, education level, occupation, job training) are introduced to the estimation. Furthermore, Badaoui et al. report that the wage gap falls to 37 percent when job characteristics (i.e. firm size, industry, supervision, urban area, part-time status, and tools) are also controlled. Following this line of research, they conclude that the observable human capital and job characteristics explain almost three quarters of average formal-informal sector wage differentials. In order to account for any possible overestimation of formal-informal earning differentials resulting from income taxation, Badaoui et al. adjust gross earnings for taxation, and find that informal-sector penalty reduces by 48 percentage points when net earnings are considered. In order to purge for time-invariant factors that may affect both selection into informal sector and wages, Badaoui et al. take the first differences of the wage equation and estimate what is known as the difference-in difference (DID) statistics. The results depict a substantial decrease in estimated wage penalty, conveying that time-invariant unobservables are indeed an important factor affecting the wage differentials. Another important contribution of the paper is the implementation of propensity score matching (PSM) method, in which one first identifies the probability of selection into the informal sector, and matches individuals accordingly, thereby creating comparable groups. Combining the PSM method with DID, Badaoui et al. obtain similar results with that of DID estimation.

Arias and Khamis (2008) apply the marginal treatment effect (MTE) methodology proposed by Heckman, Urzua, and Vytlacil (2006) to investigate the implications of labor market competitive and segmentation theories in the participation and earnings of formal-salaried, informal-salaried and self-employed workers in Argentina. The MTE method allows to account for the selection bias and sorting on the gain, thereby compare individuals indifferent at the margins of different choice and earnings. The empirical specification for participation/choice model is applied to three margins: formal-salaried work versus self-employment, informal-salaried work versus selfemployment and formal- versus informal-salaried work. Then, MTE estimations are ran for outcome/wage models in order to examine earnings differentials. The results provide evidence for both segmented and competitive informal labor markets views. For instance, formal-salaried and self-employment earnings do not exhibit any significant difference, once accounted for positive selection bias into formal-salaried work. Whereas, informal-salaried workers are found to bear significant earning penalties vis-a-vis their formal counterparts, even when controlled for the negative selection bias. 
Alzúa (2008) investigates whether the Argentinian labor markets show any evidence of dualism, two different wage setting mechanisms and rationing in the access to primary sector jobs. Considering the period 1975-2001, Alzúa estimates endogenous switching wage regression models with unknown regimes using Maximum Likelihood Search algorithms. The estimations comprise two wage equations (i.e., one for the primary and one for the secondary sectors) and a switching equation which measures the probability of being in the primary sector. One of the main contributions of the study is that the estimations are conducted without assuming ex-ante sector attachment. The results support the existence of two different wage-setting mechanisms with different returns to education and experience, thereby provide credence to the dual labor markets theory.

Bargain and Kwenda (2009) examine the informal-formal wage gap in Brazil, Mexico and South Africa using large panels. The novelty of the study is twofold. First, usual measures of wage are adjusted for the taxes paid in the formal sector which are deemed to cause overestimation of the formal sector wage premium. Secondly, time-invariant unobserved heterogeneity is accounted for by using fixed-effects quantile regression estimation proposed by Koenker (2004) and Canay (2011). The sample is designed to include only urban male aged 15-65 who are not engaged in any form of education, working as unpaid family worker or public worker; and observed at least twice consecutively. Females are excluded from the sample given that most are engaged in unpaid family work and accounting for selection into labor market is not yet standard in quantile regressions. The results reveal a similar distributional pattern of informal wage penalty across all countries. Namely, informal wage gap prevails mostly in lower earnings quantiles and disappears at the top quantiles.

Blunch (2011) contributes to the existing literature by examining the magnitude and determinants of formal-informal sector earnings gap in Serbia, specifically in the context of the recent International Financial Crisis. The empirical analysis is conducted and compared across four alternative measures of informality (firm registration, labor contract, benefit receipts and firm size) and two time periods of 2008 and 2009. In particular, Blunch first estimates the raw formalinformal sector earnings gap through Mincer wage regressions using ordinary least squares, then applies overall and detailed Blinder-Oaxaca decompositions to the observed earning gaps. The findings evince a large formal/informal sector earnings gap which somehow appears to decrease following the onset of the crisis. However, the gap does not exhibit a noticeable change when controlled for observable characteristics. The overall decomposition analysis displays that 
controlling for observable characteristics and returns to these characteristics reduces the earnings gap, yet a substantial part of the gap still remains unexplained. Furthermore, a detailed decomposition analysis indicates that many of the observable characteristics indeed widen the formal/informal sector pay differences. Most notably, education and part-time status are significantly associated with the earnings gap across all alternative informality specifications and time periods.

Falco et al. (2011) address the formal/informal employment earnings differentials using panel data from Ghana and Tanzania. First, they assume that movements in the labor market are exogenous and implement Abowd, Kramarz and Margolis (1999) framework on a standard Mincer wage equation, controlling for a set of time-varying observables including experience, firm size, sector and ability. Next, they extend the analysis by relaxing the exogenous movement assumption and allowing for possible endogeneity in sorting of workers across sectors. Following Arellano and Bond (1991) and Blundell and Bond (1998), they exploit their panel nature of the data and use the lags of time-varying job-characteristics as instruments for the first differenced and the system GMM estimators. The results depict a highly significant firm size effect and a private and public sector earning gap. Whereas, the instrumental variable (IV) estimate reveals an even higher size effect relative to that of OLS, suggesting that OLS may actually be underestimating the sector and firm size effects, as opposed to what is commonly believed.

Nguyen et al. (2011) assesses the formal/informal earnings gap using individual level panel data from Vietnam. The analysis is particularly important, since it allows for heterogeneity in the formal and informal sectors by creating four groups: formal wage workers, informal wage workers, formal self-employed and informal self-employed. The econometric methodology comprises estimations of the standard Mincer earnings equations at the means and various conditional quantiles of the earnings distributions, and a fixed effects quantile regression which controls for individual unobserved characteristics. The results suggest that formal/informal wage gap depends highly on the employment type (wage employment versus self-employment) and the position in the earnings distribution.

Günther and Launov (2012) extend the existing literature by formulating a new econometric methodology which allows for a heterogeneous structure in the informal sector. The main purpose of their analysis is to test the segmented versus competitive formal/informal labor markets theory using cross-sectional data from Cote d'Ivoire. It follows that informal workers' earnings differ 
considerably according to their segment. Indeed, the results establish that informal sector is composed of two segments, one of which displays higher levels of earnings and returns to education and experience. Accounting for any possible bias of selection into employment, Günther and Launov conclude that dual structure of informal employment indeed explains why existing empirical evidence on testing of labor market segmentation are mixed, as they mostly assume a homogenous structure of informal sector employment.

The wage gap between formal and informal sectors in Turkey was first investigated by Tansel (1999) using 1994 Turkish Household Expenditure Survey and social security coverage to identify informality. Tansel first examines how individuals are selected into employment vs nonparticipation in different sectors, then explores earnings gap between formal and informal sectors estimating selectivity corrected wage equations for each sector. The results indicate substantial wage differences between formal and informal wage earners for both men and women, thereby suggest the existence of segmentation in the Turkish labor market. In a following study, Tansel (2000) extends the analysis by incorporating the self-employed workers into the model. She follows a similar methodology and examines the factors which determine employment sector choice and wage differentials for covered and uncovered wage earners and the self-employed using Oaxaca-Blinder decomposition of sector and gender. Tansel reports that for men covered wage earners are better-off compared to uncovered wage-earners and the self-employed. Whereas, for women wages in both sectors are similar. Moreover, male wage workers who are covered earn are about twice of their female counterparts, whereas wages of male workers are found near parity with those of female workers. Overall, Tansel provides important evidence for the presence of segmentation and discrimination against women in the Turkish labor market.

Baskaya and Hulagu (2011) investigate the formal/informal sector wage gap in Turkey using cross section data from the TurkStat Household Labor Force Survey for 2005-2009 period. Firstly, they estimate a standard Mincer wage regression which incorporates a formality status dummy and control for the effects of observable individual characteristics on each sector's wage distribution. The results indicate that formal workers indeed earn significantly more than informal workers, even when controlled for observable characteristics. Baskaya and Hulagu further extend the analysis by estimating formal employment wage premium across different gender and age categories, where they find almost similar estimates across males/females and young/old. Then, they undertake a Propensity Score Matching (PSM) estimation which allows assessing the wage gap for workers with similar observable characteristics, thereby avoiding any potential bias of 
assuming formal and informal workers would have the same specification for their earning functions. The results also suggest significant wage gaps for all years under study.

\section{DATA}

The data set used in this analysis is drawn from the Income and Living Conditions Survey (SILC), which has been conducted by the Turkish Statistical Institute (TurkStat) since 2006. The novel, nationally representative, rich, panel nature of the survey makes it unique for the aim and methodology of the study. It provides detailed information on the employment status, social security coverage, working hours, labor and other income, demographic characteristics, living conditions, job characteristics, and socioeconomic conditions of the subjects. The survey results are only recently released in micro data sets, thus to our knowledge have not yet been used in any other studies.

SILC is designed as a rotating panel in which the sample of households and corresponding individuals are traced annually for four consecutive years. Each year the survey is conducted for four subsamples. One subsample is removed and replaced by a new subsample in each year. The samples are selected and assigned survey weights so as to be representative of the noninstitutionalized Turkish resident population. A two-stage stratified sampling procedure is used in sample selection. Interviews are administered once every year. The sample size is designed considering possible non-response, thereby no replacement is undertaken.

The survey results are published annually in both cross-section and panel data formats. The analysis below focuses mainly on the years 2006, 2007, 2008 and 2009, since the micro data set for the following years are not yet released. The original cross-sectional samples consist of 30,186 individuals for 2006; 30,263 individuals for 2007; 31,121 individuals for 2008 and 32,539 individuals for 2009. For the specific aim and methodology of our study, we use the panel samples which are modified in a way to comprise only the labor force between 15-64 years of age who are present in at least two consecutive years of the survey. This selection leaves an unbalanced panel of 6154 individuals who are present for two years; 3910 individuals for three years; and 1394 individuals for four years. Excluding cases with missing values for focal variables results in a sample of 23668 observations. The empirical analysis is based on this pooled sample of two, three and four year panel observations. 
Subsuming a rich set of information on household expenditure, income and assets, employment and living conditions, SILC is invaluable for implementing a detailed earnings analysis for Turkey. First and foremost, the questionnaire allows us to distinguish between employed/nonemployed, salaried/self-employed, formal/informal divides. Along these lines, we identify four different labor market states: formal-salaried, informal-salaried, formal self-employed and informal self-employed. As regards to defining informality, the first internationally agreed operational definition was adopted in the 15th International Conference of Labor Statisticians in 1993. According to this definition, informal employment was defined as comprising "all jobs in informal sector enterprises, or all persons who, during a given reference period, were employed in at least one informal sector enterprise”. Informal sector enterprises meaning enterprises that are "not constituted as separate legal entities independently of their owners, and for which no complete accounts are available that would permit a financial separation of the production activities of the enterprise from the other activities of its owner(s)" (Hussmanns, 2005:3). Put differently, informality was ascribed to small-scale enterprises; enterprises operating without a legal status and/or employing unregistered workers; and family enterprises with unpaid family workers and the self-employed (Aydin et al., 2010:3). The definition was later extended to comprise self-employed in informal enterprises (i.e. workers, employer/owner of small firms, own- account workers, unpaid contributing family members); and wage employment in informal jobs (i.e. employees in informal enterprises, casual and domestics workers, industrial outworkers) (Chen, 2007). A third definition, in official International Labor Organization (ILO) terms, considers an employment relationship as informal if it is not subject to labor legislation, social protection, taxes or employment benefits (Hussmanns, 2005:7). The social security and contract status are by and large the two most common measurement criteria in applied research.

We adopt our definitions as consistent as possible to the existing theoretical and empirical literature. Individuals are classified into four mutually exclusive groups, formal-salaried, formal self-employed, informal-salaried and informal self-employed. In this regard, the SILC questionnaire explicitly asks individuals whether they are registered at the Social Security Institution for their main job. Accordingly, employees working for a wage/salary are defined as formal-salaried if they are registered at the Social Security Institution for their current job, and informal-salaried if they are not. Own-account workers form the self-employed category, which is further divided into formal self-employed if registered at the Social Security Institution and informal self-employed if not. We exclude unpaid family workers whose earnings are difficult to measure and employers for whom the number of observations is insufficient to perform any 
reasonable analysis. By disaggregating the labor force into multiple subcategories, we are able to scrutinize the earnings gap across multiple dimensions.

As for the second important variable in our study, namely remuneration, SILC survey provides detailed information on individuals' annual income, months and hours worked on the main job. We construct our dependent variable, log real hourly earnings, first by calculating the hourly earnings then deflating it by the 2006 Turkish Consumer Price Index (CPI). Another advantage of SILC questionnaire is that wage earners and self-employed are asked different questions regarding their annual income, therefore measurement error in our analysis can be assumed as negligible. The reported earnings are net of taxes, thus we do not have to account for any overestimation that may stem from formal sector earnings being subject to tax deduction.

Besides formality status and earnings, the SILC data set also includes rich information on other variables that are associated with the level of earnings. In this study, we group these variables into three categories as individual, household and job characteristics for presentational brevity. Accordingly, individual characteristics consist of gender, age, education; household characteristics include household size, marital status, whether the household have children, household head status, whether there is a formal worker in the household; and finally job characteristics comprise sector of economic activity, occupation, firm size and part/full-time status. A comprehensive list of variables used in the analysis and their definitions are provided in Appendix Table A1.

Table 1 presents some fundamental summary statistics of the main variables used in the analysis. The statistics are reported separately for the subsamples of formal and informal employment broken down into wage/self-employment. At first sight, the results clearly reveal a sizable earnings differential between the formal and informal employment, where earnings of formal workers are almost three times that of informal workers'. However, when the earnings gap is decomposed into wage/self-employment we observe that wage employees earn more on average than the self-employed. In other words, among each group of formal and informal employment, wage earners are better off compared to the self-employed workers.

The gender variable indicates that male workers dominate employment in any type. Indeed, females constitute only one fifth of each group of employment, except for the informal wage work category where they are even more marginal at only four percent. In terms of age, we see 
that formal workers tend to be younger on average than informal workers. Also notable, formal self-employed workers appear mostly in the younger age groups, whereas informal self-employed workers tend to concentrate in the older age groups.

Education, confirming the conventional wisdom, exhibits a positive (negative) relationship with formal (informal) employment. On average, formal workers are better educated than informal workers; especially those in wage employment. More specifically, almost 50 percent of those who are formally employed have a high school or above degree, whereas for informal employees corresponding number remains at only 13 percent. Considering the wage/self-employment divide, the self-employed tend to have significantly lower levels of education compared to wage workers. As for experience, the results reveal that informal workers have on average more years of experience in the labor market, especially those who are informal self-employed.

In terms of the household characteristics, the summary statistics demonstrate that employment in all types are dominated by those who are married and have children. Being head of the household displays a stronger association with being an informal worker, whether wage or self-employed. Household size does not show any differentiable pattern across formal/informal or wage/selfemployment jobs.

Proceeding with employment characteristics, an initial look at the sector summary statistics displays two notable patterns. First, agricultural employment mostly prevails as informal selfemployment and second, manufacturing is predominantly a formal sector. Except for these two large sectors of, distribution of formality is quite dispersed for the other sectors. Specifically, informal employment appears larger in construction and trade, whereas formal workers are often concentrated in energy, public administration and education. Across the wage/self-employment divide, a few points are worth to mention. Formal employment in construction and agriculture sectors, though minimal when compared to informal employment are typically in the form of selfemployment. The distribution of formality across different occupations does not indicate any noticeable pattern. We also observe that informal employment is concentrated mostly in small firms; as compared to formal employment which is predominantly present in large firms. Finally, part-time job holders are more likely to be informal, particularly if informal self-employed.

The summary statistics, overall, indicate that formality/informality of jobs is associated with several observed and unobserved characteristics and is unlikely to be randomly assigned across 
different employment types. From an empirical standpoint, this fact constitutes the main challenge in estimating the existence of an earnings gap between the two sectors. In order to deal with such a potential sample selection bias, as it is called, we exploit the panel nature of our data to account for time-invariant unobservable effects and several individual and job characteristics as explanatory variables to control for the observable effects.

\section{EMPIRICAL METHODOLOGY}

As Badaoui et al. (2008:693) argue: "the problem of measuring any potential informal-sector wage penalty boils down to trying to answer the following counterfactual question: what wage would a person employed in the informal sector have if he or she was instead employed in a similar job in the formal sector?”. In other words, the main challenge in earnings gap analysis is to control possible sample selection bias which may result from either self-selection of individuals into different employment types or non-participation based on own cost-benefit calculations, or some methodological selection of researchers. In order to refrain from any selection bias that is associated with selection into employment or non-participation, we restrict our sample into employed individuals, following recent studies which take the same approach such as Bargain and Kwenda (2010) and Badaoui et al. (2008). Once an individual is employed, however, there is another potential selection bias which involves selection into different types of employment. Indeed, there are several observable and unobservable factors which affect both selection and the level of earnings. As shown in the summary statistics, formal and informal workers are not only different in terms of remuneration, but also of personal and job characteristics. To this end, we take advantage of the rich information in our data set and control for various observable individual, household and job characteristics in our estimations. And as for the unobservables, we rely on the rotating panel nature of our data which enables isolating the time-invariant individual fixed effects, and thereby alleviates some of the concern regarding their influence on one's earnings. For gender-specific selection issues, we perform all estimations separately for male and female subsamples.

Following this line of approach, our empirical strategy consists of estimating the two different specifications of the formal/informal earnings gap, one at formal/informal divide and the other at the wage/self-employment divide, using OLS, quantile and fixed effects regressions. In this way, we are able to disentangle earnings differentials not only across formal/informal employment, but also across wage/self-employment. 
The analysis is based on the seminal human capital earnings model of Mincer (1974), which can be traced back to the human capital theory of Becker $(1962,1964)$, Schultz $(1960,1961)$ and Mincer $(1958,1962)$. The model postulates that three main determinants of individual wages are education, work experience and its square. As with most studies, we extend the model by including a number of variables which are frequently used in the empirical literature to explain returns to human capital characteristics and earnings of individuals. In order to estimate the formal/informal earnings gap, we specify the following Mincer earning models:

$w_{i t}=\alpha+\beta I_{t t}+\gamma X_{t t}+\varepsilon_{t t}$

where $t=[1, \ldots, N]$ represents individual units and $t=\{1, \ldots, T \mathbf{\}}$ time periods. The dependent variable $w_{i \pm}$ refers to the log real hourly earnings; $X_{i \pm}$ denotes the set of individual, household and job characteristics of individual i observed at time t. ${ }^{2}$ The different covariates include hours worked per week, experience, gender, age, education, household size, household head status, presence of children in the household, presence of a formal worker in the household, marital status, economic sector, occupation, firm size and part/full-time job status. The dummy variable $I_{i t}$ takes the value of one if individual is informal and zero otherwise. The estimated coefficient $\bar{\beta}$ will be used to test whether there exists a wage penalty/premium for informal employment visa-vis formal employment.

In the same manner, we will extend the analysis into wage/self-employment divide, in order to account for the heterogeneity inherent within the formal and informal sectors. As defined in the previous section, we consider four employment types as formal-salaried, informal-salaried, formal self-employed and informal self-employed. Accordingly, we create four dummy variables indicating each employment type, specifically $F S_{t}$ for the formal-salaried; $I S_{t}$ for the informalsalaried; $F S E_{i=}$ for the formal self-employed and $I S E_{i t}$ for the informal self-employed. For this empirical specification, we take the reverse approach and identify the informal-salaried as the base category. Along these lines, the extended model can be formulated as:

$w_{t t}=\alpha+\beta F S_{t t}+\theta F S E_{t t}+\delta I S E_{t t}+\gamma X_{t t}+\varepsilon_{t t}$

\footnotetext{
${ }^{2}$ For the definitions of the set of individual, household and job characteristics that are represented by $X_{i z}$, see Appendix Table A1.
} 
The estimated coefficients $\vec{\beta}, \vec{\theta}$ and $\vec{\partial}$ are interpreted as the conditional earnings gap between the informal-salaried workers and formal-salaried, formal self-employed and informal self-employed workers, respectively.

First, standard earnings equations are estimated at the mean using OLS in levels on a pooled sample of workers over years. For this particular estimation, we specify the following wage equations:

$w_{t t}=\alpha+\beta I_{t t}+\gamma X_{t t}+\pi \cdot t m e+\varepsilon_{t t}$

$w_{t t}=\alpha+\beta E S_{t t}+Q F S E_{t t}+\delta I S E_{t t}+\gamma X_{t t}+\pi \cdot \operatorname{tim} \theta+\varepsilon_{t t}$

We will start by estimating equations (3) and (4) using only the employment type dummies (i.e. formal or informal) and year dummies. A year dummy is intended to capture all effects that are common at a given point in time. However, as displayed in the summary statistics, formality of jobs is related to several observable individual and job characteristics. Following this manner, we will proceed our estimation by first including individual and household characteristics, then further extending it by introducing job characteristics. In this way, we aim to understand the extent to which observable characteristics explain the average earnings differentials across formal/informal employment. Moreover, we conduct the analysis not only for the whole sample, but also for male only and female only samples in order to take into account of gender dynamics that often impede empirical analysis.

Considering the fact that estimations at the mean tend to conceal important information, we will rely on quantile regressions (Koenker and Bassett, 1978) to estimate earnings gap on our pooled sample. Quantile estimation, as put by Nguyen et al. (2011:12), enables analyzing the earnings gap at different points of the earnings distribution. In this way, we aim to capture the heterogeneity in returns to observed characteristics along the conditional quantiles of the earnings distribution. We implement the following QR models which specify the $Q$ th conditional quantile of the log real hourly wage ( $w_{i t}$ ) distribution for individual $i$ at time $t$ as:

$\left.q_{Q}\left(W_{t t}\right)=\alpha_{Q}+\beta_{Q} I_{t t}+\gamma_{Q} X_{t t}+\varepsilon_{t t}, \quad Q \in \mathbf{C} 0,1\right)$ 
$\varphi_{Q}\left(w_{i t}\right)=\alpha_{Q}+\beta_{Q} F S_{t t}+\theta_{Q} F S E_{i t}+\delta_{Q} I S E_{i t}+\gamma_{Q} X_{i t}+\varepsilon_{i t}$

where the set of coefficients demonstrate the estimated returns to the covariates at the $\theta$ th quantile of the $\log$ real hourly wage distribution. In particular, $Y_{g}$ in both QR specifications depicts the effects of changes in the set of individual and job characteristics on the $Q$ th quantile of $w_{i t}$. In model (5), $\beta_{\mathscr{Q}}$ measures the extent to which informal employment wage penalty/premium vis-à-vis formal employment wage remains unexplained at the various quantiles after controlling for individual and employment characteristics. Whereas, in model (6), $\beta_{Q}, \theta_{Q}$ and $\delta_{\Omega}$ refer to the earnings differentials at the $\theta$ th quantile between informal-salaried workers and formal-salaried, formal self-employed and informal self-employed workers, respectively. The quantile regression coefficients in model (5) are straightforward to estimate by minimizing:

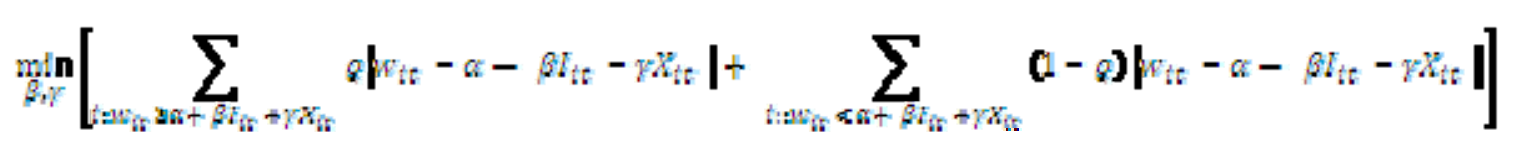

Similarly, coefficients for model (6) can be estimated following the same fashion.

Having controlled for several observable characteristics by using OLS and quantile regressions, we next exploit the panel nature of our data set and estimate Fixed Effects OLS regressions. In this way, we are able to account for the time-invariant unobservable factors that may be obscuring more accurate measures of the earning differentials. The FE models can simply be written as:

$w_{t t}=\alpha_{t}+\beta I_{t}+\gamma X_{t t}+\mu_{t}+\varepsilon_{t t}$

$w_{t t}=\alpha_{t}+\beta F S_{t t}+Q F S E_{t t}+\delta I S E_{t t}+\gamma X_{t t}+\mu_{t}+\varepsilon_{t t}$

where $\mathrm{E}\left[\boldsymbol{s}_{1}(t) \mid \mu_{4}(t), X_{1}(t), I_{1}(t)\right]=0$ for all individuals $i$ and periods $t$. In this panel specification, $\mu_{i}$ denotes the time-invariant unobserved individual fixed effects and $\varepsilon_{i t}$ is normally i.i.d. stochastic term absorbing the measurement error. In model (7), the estimated coefficient $\vec{\beta}$ measures the conditional informal employment earnings premium/penalty vis-à-vis formal employment. As follows, coefficient estimates $\bar{\beta}, \bar{\theta}$ and $\bar{\delta}$ in the model (8) can be interpreted as the conditional earnings gaps between informal-salaried workers and respectively, formal-salaried, formal self-employed and informal self-employed workers. For identification of 
these conditional earnings gaps, one should verify that there is a sufficient number of movers in the sample who change their employment states over time as well as stayers who remain in their state. Denoting the four alternative employment states FS, FSE, IS, ISE with $K=1,2,3,4$ respectively, identification issue can be illustrated by a simple two-period example and four of the possible transitions :

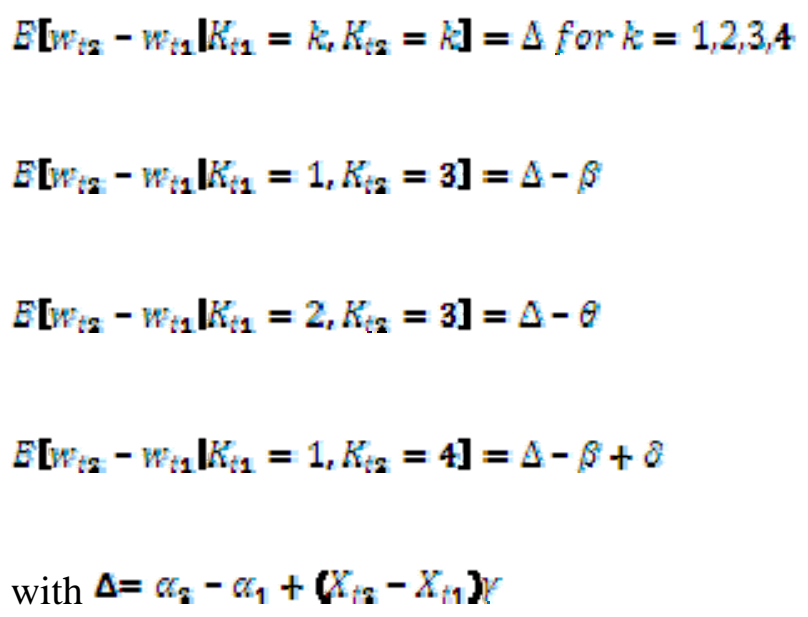

Equation (9) illustrates the changes in the earnings of stayers; equations (10) and (11) represent earnings differentials for workers moving from formal-salaried and formal self-employment, respectively into informal-salaried employment; and equation (13) shows the earnings changes for those moving from formal-salaried to informal self-employment. Nevertheless, there are 16 possible permutations between states and we verify that the number of movers for each possible transition is sufficient for a valid use of the FE estimator by constructing transition matrices across possible employment states. ${ }^{3}$ As Bargain and Kwenda (2009:8) state: “the FE estimator is consistent even if unobserved characteristics are correlated with both selection and wages, as long as those characteristics are constant over time".

Before proceeding to estimation results, a few empirical points should be addressed. First and foremost, the issue of selection into employment is often accepted to be crucially important in such analysis. Indeed, as Tansel and Kan (2012:12) report a substantial majority of the working age population in Turkey is classified as out of labor force. In order to alleviate potential sample selection bias, we restrict our sample to employed individuals as done in several other studies. Also taking account of the intrinsic differentials in male and female labor force participation

\footnotetext{
${ }^{3}$ For presentational brevity, the results of the transition analysis are not reported but available upon request.
} 
rates, we run our estimations separately for male and female subsamples. And most importantly, we assume that the panel nature of our data which allows controlling for time-invariant unobservables affecting earnings also controls for selection. Finally, we define our dependent variable as the $\log$ hourly earnings, i.e. hourly wage rates for the wage workers and their equivalent for the self-employed. The SILC questionnaire allows us to identify the earnings of wage and self-employed workers accurately as it employs specific earnings questions for each type of employment.

\section{RESULTS}

\subsection{Pooled Ordinary Least Squares (OLS)}

\subsubsection{Earnings Gap Across Formal/Informal Employment}

We start by estimating the formal/informal employment earnings gap using OLS in levels. First, we begin with a model which includes only the informal worker dummy and year dummies. The results, reported in the first column of Table 1, indicate a significant wage penalty for informal employment amounting to 53.9 percent. However, as we have mentioned previously, differences in earnings can be attributed to several observable and unobservable factors. Following this line of thought, we first introduce a number of individual and household characteristics into our earnings model, and re-estimate the earnings gap. The results, given in the second column of Table 1, show that informal earnings penalty indeed falls considerably to 31.8 percent. Put differently, almost half of the earnings differences between formal and informal employment can be explained by the observable individual and household characteristics. Further extending the model by incorporating the job aspects, we again detect a significant but lower informal earnings penalty of 21.5 percent. As Badaoui et al. (2008:695) remark one may argue that some of these job characteristics are almost exclusively concurrent with informal sector, still the results of this exercise provides an important initial insight into the earnings differentials. In brief, OLS analysis confirms the existence of an informal sector earning penalty, but also show that more than half of this pay difference is indeed explainable by observable factors.

A gender breakdown of formal/informal earnings analysis is of crucial importance for several reasons, particularly in the context of Turkish labor market. First, the incidence of inactive women still stands as a major virtue of the Turkish labor market; thence distorts most aggregate labor market figures. As regards to informality, Tansel and Kan (2011:6) report that almost two 
thirds of those women who are employed are informal, while men exhibit a more or less equal distribution across informal and formal sectors. They also find that men are mostly employed in salaried positions and women in self-employment positions. In our analysis, we alleviate the empirical implications related to gender to some extent by excluding from the sample those in agricultural and unpaid family work where most female employment is present. Nevertheless, we believe that a gender breakdown still deserves an interest though without going into much detail.

When we re-estimate the OLS in levels separately for male and female subsamples, we see that female workers suffer a substantially higher level of informal earnings penalty. More specifically, we find that the raw earnings penalty stands at -0.707 for female subsample, whereas it is quite lower at -0.505 for the male sample. When controlled for individual and household characteristics, despite decreases in magnitude, there still remains a considerable unexplained informal pay penalty of 25 and 45 percent for males and female workers, respectively. Put differently, women still appear to experience a wage penalty almost twice of those born by male workers. This finding suggests that returns to personal attributes constitute an important determinant of male workers' earning differentials, whereas for female workers they are less significant. This results may be interpreted as a reflection of discrimination against women. However, once all observable characteristics are introduced into the model, the negative informal premium for females also falls substantially, and becomes almost equal to that for male workers. This finding may be a reflection of the fact that women are mostly employed in jobs which are intrinsically informal in its nature.

\subsubsection{Earnings Gap Across Formal-salaried/Informal-salaried/Formal self-employed/ Informal self-employed}

A further breakdown of the formal/informal earnings gap including wage/self-employment divide is expected to disseminate a more detailed portray given that both of these sectors embody sizable heterogeneity. For this analysis, however, we choose to identify informal-salaried workers as the base category and interpret the estimation results accordingly. Nevertheless, the implications of the results do not change.

Considering the raw earnings differentials, estimation results in the first three columns of Table 2 appear to confirm the traditional theory that informal-salaried workers on average earn significantly less than those who are formally employed, whether salaried or self-employed. In particular, wage workers who are formally employed earn approximately 50 percent higher than 
those who are informally employed. Once controlled for personal attributes, as reported in column two of Table 2, formal premium decreases to around 30 percent, but still remains to be significant. With the introduction of job characteristics, formal/informal wage differentials exhibit a notable fall and becomes 18 percent. Overall, the results suggest that there indeed exists a positive pay premium for formal wage workers compared to their informal counterparts. This evidence appears to be in line with the conventional wisdom that informal wage employment is on average subject to lower remuneration.

An interesting result can be observed when earnings differences of informal-salaried and formal self-employed are considered. In particular, the size of earnings gap, which is around 30 percent, appears to remain robust against the inclusion of additional explanatory variables. Put differently, personal and job characteristics explain the pay differences to only a minimal extent. This finding is mostly likely the result of informal-salaried and formal self-employed jobs and workers being utterly different in nature, thereby rendering the earnings gap unexplained.

Also noteworthy is the comparison of the earnings gap between different types of informal employment. As per se, informal self-employed are observed to be significantly worse-off than informal-salaried workers but only when individual and job characteristics are introduced to the Mincer equation. Indeed, the initial raw estimate though having a negative is not significant, but becomes significant as observables are taken into account. To this end, one can claim that informal-salaried workers on average have better observable characteristics than their selfemployed counterparts, and once returns to these attributes are considered they are infact significantly lower paid.

We next replicated our analysis separately for the male and female subsamples. We find that the picture somewhat alters but the changes are mostly limited to earning differentials within informal employment itself. In particular, pay gap between informal-salaried and informal selfemployed is almost insignificant for male workers. Whereas for the female subsample, the coefficient of informal self-employment is highly significant under all specifications of the model. In particular, informal self-employed female workers are paid around 40 percent less than their salaried counterparts. It is also interesting to note that the earnings penalty increases sharply to 70 percent if we control for individual and household effects. This finding implies that monetary returns to similar personal attributes are considerably lower in informal selfemployment compared to informal wage employment. The penalty falls back to 40 percent when 
job attributes are also incorporated into the model. Overall, these results indicate that females are more prone to hold lower-tier informal jobs which have inferior earnings in contrast to males clustering at higher-tier informal jobs where pay differentials between wage and self-employment are insignificant.

\subsection{Pooled Quantile Regression (QR)}

\subsubsection{Earnings Gap Across Formal/Informal Employment}

Estimations at the mean are generally insufficient when covariates affect not only the location of the conditional distribution of wages, but also its dispersion. Therefore, one has to go beyond a simple mean estimation model and apply quantile regression for a more comprehensive and informative analysis. Therefore we extend our empirical analysis by estimating conditional quantile regression (QR), as given in equations (5) and (6), on our pooled sample. This exercise allows for tracking the earnings gap along various conditional quantiles of the earnings distribution, thereby unveil more complex dynamics pertained to pay differentials.

The quantile regression estimates, reported in Table 3a, depict that informal employment earnings penalty is larger at lower quantiles but decreases significantly in higher quantiles, even after several observable individual and job characteristics are controlled for. In particular, the coefficient of informal variable which is -0.593 in the $5^{\text {th }}$ quantile gradually falls as we move along the earnings distribution and eventually emerges as insignificant around $90^{\text {th }}$ quantile. More interestingly, the informal earnings gap becomes significantly positive at the top quantile. The large earnings penalty in the lower quantiles may be thought of as affirming the traditional segmentation theory which views informal employment as an inferior state. However, confirming our basic premise of a heterogeneous informal sector, the earnings gap is infact not uniform along the distribution and turns into a premium at the top. The last finding reveals that upper-tier informal jobs which are voluntarily chosen by workers given their preferences, personal attributes and competing earning prospects are concentrated in the upper income levels. In order to further scrutinize the underlying dynamics of these findings, we will re-estimate the gap considering not only formal/informal but also wage/self-employment divide in the following section.

The results of the gender decomposition of the QR are qualitatively similar to the analysis of the entire sample and changes are quantitatively small. More specifically, both female and male informal workers are found to experience significant earnings penalties at the lower quantiles of 
the earnings distribution. The magnitude of the informal penalty is only marginally higher for female workers. One may also note that formal/informal earnings differences becomes insignificant for female workers at the $75^{\text {th }}$ quantile and displays a significantly positive sign at the top quantile. Whereas for male workers, the informal wage penalty disappears at the 90th quantile and is statistically insignificant afterwards. This is a particularly interesting result since it shows that upper-tier informal jobs are considerably more rewarding for female workers. The informal premium for female workers at the top which reaches almost 35 percent may also be an indication of positive discrimination towards women against men given similar observable personal and job characteristics.

\subsubsection{Earnings Gap Across Formal-salaried/Informal-salaried/Formal self-employed/}

\section{Informal self-employed}

A further breakdown of the formal/informal earnings gap by incorporating wage/self-employment divide empowers a more thorough examination. Several theoretical and empirical studies address the issue of intrinsic heterogeneity within the formal and informal sectors, and suggest that more accurate and informative analysis requires it to be acknowledged. In this section, we report and discuss the conditional QR estimation results of the Mincer wage function where informalsalaried workers are taken as the reference category. The first row in Table 4a confirms the conventional wisdom that within salaried employment, formal workers have significantly higher earnings than their informal counterparts, given identical personal and establishment characteristics. However, this formal sector premium for salary workers decreases gradually with the earnings level, and eventually becomes negative at the top. The results point to the dual nature of informal sector, with upper-tier jobs carrying an earnings premium that may compensate the benefits of formal wage work and lower-tier jobs being largely penalized. One may also claim that formal-salaried workers have better unobservable skills compared to their informal counterparts considering the fact that results are obtained by controlling for only observable characteristics. To further investigate this, we will next apply the fixed effects estimation to earnings gap which allows for controlling for unobservable heterogeneity.

Turning to earnings differentials between formal self-employed and informal-salaried workers, as reported in the second row of Table 4a, we detect a significantly positive gap at all quantiles. Put differently, formal self-employed are better-off along the whole distribution, though the size of their earnings premium falls with increased income levels. This finding may be the result of either better unobserved skills of formal self-employed workers or pure intrinsic premium in the formal 
self-employment.

A comparison which deserves particular interest the pay gap is between informal salary vis-a-vis self-employed workers. The QR estimates in the third row of Table 4a demonstrate that informal self-employed suffer a significant earnings penalty but only at the lower end of the distribution of the $5^{\text {th }}, 10^{\text {th }}$ and $25^{\text {th }}$ quantiles. Afterwards, the gap becomes insignificant for the upper half. Overall, the evidence clearly demonstrates the heterogeneity within informal sector; where the lower end corresponds to segmented and upper quantiles to competitive labor markets theories. In contrast to the mainstream literature which views informal self-employed as the upper-tier and wage earners as the lower-tier, our findings suggest that lower-tier informal employment corresponds to self-employment in the Turkish labor market.

When the analysis is replicated for male and female subsamples separately, we detect a number of discernible patterns. For male workers, the significantly positive formal wage premium decreases with earnings level and disappears at the $90^{\text {th }}$ quantile. Moreover, for the richest male workers at the top of the distribution, informal-salaried employment offers significantly higher remuneration compared to formal-salaried employment, though at a marginal rate of 8 percent only. Formal self-employed male workers are associated with relatively higher earnings compared to informalsalaried throughout the entire distribution. For the lower end, formal self-employment premium amounts to 40 percent, but halves to approximately 20 percent for $25^{\text {th }}$ and higher quantiles. The earnings gap between informal wage and self-employment reveals a somewhat ambivalent picture, as reported in the third row of Table $4 \mathrm{~b}$. Only at the lowest quantile, male informal selfemployed suffer a 10 percent penalty compared to male informal wage workers. This result conforms to the segmentation theory and our previous finding that self-employed form the lowertier informal employment. For higher quantiles, however, this earnings penalty disappears and becomes significantly positive at the $75^{\text {th }}$ quantile. The implications are twofold: informal selfemployed workers at the upper end of the earnings distribution may have better unobserved skills and thus earn higher monetary returns or informal self-employment jobs at the upper quantiles may have better earnings prospects compared to informal-salaried positions by their nature.

The distributional pattern of earnings gap becomes even more discernible when the analysis is limited to female subsample. The first thing to notice in Table 4c is that the formal wage premium at the lower half of the earnings distribution completely vanishes at the upper half. This result provides evidence for the presence of labor market segmentation at the lower end, but also shows that this may not apply to workers at the top. Indeed, the results show that the 48 percent formal- 
salaried wage premium at the lowest quantile turns into a 42 percent penalty at the top. Comparing with the corresponding figure for male workers which is only 8 percent, this result is particularly intriguing. One can argue that this may be solely due to better unobserved skills of informal-salaried individuals at the 95th quantile which are rewarded with higher pay. However, such a result is often taken to be an evidence of heterogeneity in the informal sector, lower-tier being subject to worse pay conditions in contrast to upper-tier having better remuneration. Turning to the earnings gap between formal self-employed and informal-salaried female workers, we do not observe any pronounced pattern as was found in the male subsample. This is most likely due to female formal self-employment being almost negligible in the Turkish labor market. Last but not least, we observe that informal self-employed female workers are consistently worseoff than their salaried counterparts throughout the earnings distribution. In contrast to the results for all and male samples, the coefficient of informal self-employment does not become positive at the top quantiles. This finding is also of particular importance as it clearly demonstrates that informal self-employment constitutes the lower end for female workers, where remuneration is always worse than salary work.

\subsection{Fixed Effects}

\subsubsection{Earnings Gap Across Formal/Informal Employment}

Time-invariant unobserved individual heterogeneity is accepted to play an important role in explaining the formal/informal earnings gaps, even after controlling for a rich set of observable individual- and job-level characteristics. El Badaoui et al. (2008:697) claim that there are often several unobservable factors which determine both selection desicion into the formal/informal employment and wages, thereby if not taken into account will lead to biased estimates of the earning gaps. Similarly, Abowd et al. (1999) report that $\mu_{i}$ are by far the most important factor in determining earnings. Following this line of thinking, we exploit the panel nature of our data and rely on fixed effects estimation to purge such unobservables, thereby isolate their effect on pay differences. The estimation results for the two model specifications, equations (7) and (8), are provided in Tables $5 \mathrm{a}$ and $5 \mathrm{~b}$, respectively.

Overall the results are quite remarkable: when accounted for time-invariant unobservables, formal/informal earnings differentials are not found to be statistically significant. Put differently, unobserved individual fixed effects when combined with controls for observable personal, household and job characteristics explain pay differences entirely. By examining male workers, 
however, one finds evidence that there still remains a 10 percent informal penalty which is statistically significant at 10 percent level of significance. Female workers do not experience any significant earning differential across formal/informal employment after controlling for all observable and unobservable factors which are likely to determine the level of earnings. The implications of results are threefold. Segmentation may not be a stylized fact of the Turkish labor market as commonly believed once unobserved individual effects are accounted for. Secondly, formal sector workers on average have better unobserved characteristics, as well as better observable attributes. Once these factors are accounted for, the informal earning penalty entirely disappears.

\subsubsection{Earnings Gap Across Formal-salaried/Informal-salaried/Formal self-employed/}

\section{Informal self-employed}

When replicated for the second Mincer specification, equation (8), results are qualitatively similar to previous findings. Specifically, the fixed effects estimation displays that there is no statistically significant earnings gap between formal- and informal-salaried workers. Whereas, for male wage earners, we find a 10 percent formal premium. Though not statistically significant, the coefficient of formal-salaried emerges as negative for female wage workers, implying a formal penalty.

Formal self-employed workers appear to be significantly better-off than informal-salaried, even after controlling for individual fixed effects. However, further breakdown of the sample show that this finding loses relevance when sample is restricted to females only.

As for within informal employment earnings differentials, we find no statistically significant gap once we control for unobservable factors using fixed effects regression. Again for the females, however, it is statistically significantly negative, implying the existence of an earning penalty for the informal self-employed when compared to their salaried counterparts.

\section{CONCLUDING REMARKS}

In this study, we examine the formal/informal sector earnings differentials in the Turkish labor market in terms of its prevalence, magnitude and underlying dynamics. For this purpose, we employ detailed econometric methodologies and a novel panel data set drawn from the 20062009 Income and Living Conditions Survey (SILC) which subsumes a rich set of information on individual, household and employment characteristics; income and labor market state. In 
particular, we test if there is evidence of traditional segmented labor markets theory which postulates that informal workers are typically subject to lower remuneration than similar workers in the formal sector. Moreover, we address the heterogeneity within the formal and informal employment by further decomposing our analysis based on wage and self-employment. The empirical analysis consists of examining the earnings gap along multiple dimensions, disentangling at formal/informal sector, wage/self-employment, and mean/quantiles of the earnings distribution. All of the analyses are also replicated for male and female subsamples separately.

First, we estimate standard Mincer earnings equations at the mean using OLS on a pooled sample of workers. Across formal/informal divide, the results indicate a significant raw penalty for informal workers, which tends to decrease as other earning-related variables (i.e. individual, household and job attributes) are included in the regression. Overall, the analysis confirms the existence of an informal penalty, but also shows that almost half of this penalty can be explained by observable variables. We also find that the unexplained informal penalty for female workers is twice of that for the male workers when only individual characteristics are controlled for demonstrates that returns to personal attributes are comparatively lower for female workers, hence implying the presence of discrimination against women. However, once job variables are also introduced to the model, informal penalty for female workers is at parity with that for male workers. Turning to formal/informal pay differences along wage/self-employment divide, our results are in line with the traditional theory that formal-salaried workers are paid significantly higher than their informal counterparts. Confirming the heterogeneity within informal employment, we find that self-employed are often subject to lower remuneration compared to those who are salaried.

Acknowledging the fact that earnings at the mean are not so informative, we next estimated quantile regressions on our pooled sample. Indeed, the results show that pay differentials are not uniform along the earnings distribution. More specifically, we find that informal penalty decreases with the earnings level, i.e., it is significant at the lower quantiles but either becomes insignificant or even turns into a premium at the top. The results, overall, confirm our basic premise of a heterogeneous informal sector upper-tier jobs carrying a significant premium that may compensate the benefits of formal wage work and lower-tier jobs being largely penalized. An important finding revealed by the distributional analysis is that, in contrast to the mainstream literature which views informal self-employed as the upper-tier and wage earners as the lower- 
tier, lower-tier informal employment indeed corresponds to self-employment in the Turkish labor market. The distributional pattern of earnings gap becomes even more discernible when the analysis is limited to female workers. Most notably, the 48 percent formal-salaried wage premium vis-a-vis informal-salaried at the lowest quantile turns into a 42 percent penalty at the top. This result also affirms the dual nature of informal sector.

Finally, we estimate fixed effects regression exploiting the panel nature of our data in order to take into account of time-invariant unobservable characteristics that are also deemed as important determinants of earnings levels. The results show that unobserved individual fixed effects when combined with controls for observable individual and employment characteristics explain the pay differentials between formal and informal employment entirely. The implication is particularly remarkable, that formal/informal segmentation may not be a stylized fact of the Turkish labor market as previously thought. Indeed, further breakdown by gender also displays only a slightly significant informal wage penalty for male workers and no statistically significant informal pay gap for female workers. When FE model is extended to incorporate salaried vs. self-employment divide, we observe three noticable patterns. First, there is no evidence of a statistically significant earnings gap between formal and informal wage earners, but only for the male sample which displays a slightly significant 10 percent formal premium. Second, formal self-employed workers display earnings premiums of 15 and 21 percents, respectively for all and male only samples. As for within informal employment, earnings differentials in favor of salaried work against selfemployment ceases to exist when one accounts for time-invariant unobservables. The 40 percent earnings penalty for female informal self-employed, however, confirms our prior evidence that self-employment rather corresponds to lower-tier informal employment even after controlling for many observable and unpbservable factors.

To conclude, the analysis provides a comprehensive and detailed diagnosis of formal/informal pay differentials in the Turkish labor market. Using a panel data set and several econometric approaches, we indeed detect an informal sector penalty, but once controlled for observable and unobservable effects the gap disappears entirely, thereby disproves the existence of labor market segmentation in Turkey. 


\section{REFERENCES}

Abowd, J.M., F. Kramarz and D.N. Margolis (1999). "High wage workers and high wage firms”, Econometrica, 67(2), 251-333.

Amuedo-Dorantes, C. (2004). "Determinants and Poverty Implications of Informal Sector Work in Chile”, Economic Development and Cultural Change, 52(2), 347-68.

Arias, O. and M. Khamis (2008). “Comparative Advantage, Segmentation and Informal Earnings: A Marginal Treatment Effects Approach”, IZA Discussion Papers No.391.

Alzúa, M. L. (2008). “Are informal workers secondary workers? Evidence for Argentina”, CEDLAS Working Papers No.73.

Arellano, M. and S. Bond (1991). "Some tests of specification for panel data: Monte Carlo evidence and an application to employment equations”, Review of Economic Studies, 58, 277-297

Badaoui, E., E. Strobl and F. Walsh (2008). "Is there an Informal Employment Wage Penalty? Evidence from South Africa”, Economic Development and Cultural Change, 56, 683-710.

Bargain, O. and P. Kwenda (2009). “The Informal Sector Wage Gap: New Evidence Using Quantile Estimations on Panel Data”, IZA Discussion Papers No.4286.

Bargain, O. and P. Kwenda (2010). "Is Informality Bad? Evidence from Brazil, Mexico and South Africa”, IZA Discussion Papers No.4711.

Basch, M. and R. D. Paredes-Molina (1996). “Are there dual labor markets in Chile?: empirical evidence”, Journal of Development Economics, 50, 297-312.

Baskaya, Y. S. and T. Hulagu (2011). "Informal-Formal Worker Wage Gap in Turkey : Evidence From A Semi-Parametric Approach”, Central Bank of the Republic of Turkey Working Papers No.1115.

Becker, G. S. (1964). Human capital: A theoretical and empirical analysis, with special reference to education, Columbia University Press, New York.

Bernabe, S. (2002). "Informal Employment in Countries in Transition: A conceptual framework", CASE Papers No. 56, Centre for Analysis of Social Exclusion, LSE.

Blunch, N. H., S. Canagarajah and D. Raju (2001). “The Informal Sector Revisited: A Synthesis across Space and Time”, Social Protection Discussion Paper Series No. 0119, The World Bank.

Blundell, R. and S. Bond (1998). "Initial conditions and moment restrictions in dynamic panel data models”, Journal of Econometrics, 87, 115-143.

Carneiro, F.G. and A. Henley (2001). "Modelling formal vs. informal employment and earnings: micro-econometric evidence for Brazil”, University of Wales Aberystwyth School of Management and Business Research Paper No. 2001-16. 
Canay, I. A. (2011). “A simple approach to quantile regression for panel data”, Econometrics Journal, 14(3), 368-386.

Chen, M. (2007). "Rethinking the Informal Economy: Linkages with the Formal Economy and the Formal Regulatory Environment”, Department of Economics and Social Affairs (DESA) Working Papers No. 46.

Cohen, B. and W.J. House (1996). "Labor market choices, earnings and informal networks in Khartoum, Sudan”, Economic Development and Cultural Change, 44(3), 589-618.

Cunningham, W. and W. F. Maloney (2001). “Heterogeneity among Mexico’s Microenterprises: An Application of Factor and Cluster Analysis”, Economic Development and Cultural Change, 50, 131-156.

Falco, P., A. Kerr, N. Rankin and J. Sandefur and F. Teal (2011). "The returns to formality and informality in urban Africa”, Labour Economics, 18(1), S23-S31.

Fields, G. S. (1975). "Rural-Urban Migration, Urban Unemployment and Underemployment, and Job-Search Activity in LDC's”, Journal of Development Economics, 2, 165-187.

Fields, G. S. (1990). "Labour market modelling and the urban informal sector: theory and evidence” in D. Thurnham, B. Salomé and A. Schwarz (Eds), The Informal Sector Revisited, OECD, Paris.

Fields, G. S. (2005). “A guide to multisector labor market models”, Social Protection Discussion Paper Series No. 0505, The World Bank.

Gindling, T. (1991). "Labor market segmentation and the determination of wages in the public, private-formal and informal sectors in San-Jose, Costa-Rica", Economic Development and Cultural Change, 39(3), 585-603.

Gong, X. and A. van Soest (2002). "Wage differentials and mobility in the urban labour market: a panel data analysis for Mexico”, Labour Economics, 9(4), 513-529.

Günther, I. and A. Launov (2006). “Competitive and Segmented Informal Labor Markets”, IZA Discussion Papers No. 2349.

Günther, I. and A. Launov (2012). "Informal employment in developing countries: opportunity or last resort?”, Journal of Development Economics, 97, 88-98.

Heckman, J. J. (1981). "Statistical models for discrete panel data", in C. Manski and D. McFadden (Eds.), Structural Analysis of Discrete Data with Econometric Applications, 114-178, MIT Press, Cambridge.

Heckman, J. J. and V. J. Hotz (1986). "An Investigation of the Labor Market Earnings of Panamanian Males: Evaluating the Sources of Inequality", Journal of Human Resources, 21, 507-542.

Heckman, J. J., S. Urzua and E. J. Vytlacil (2006). "Understanding instrumental variables in models with essential heterogeneity”, Review of Economics and Statistics, 88, 389-432. 
Henley, A., G.R. Arabsheibani and F.G. Carneiro (2009). "On defining and measuring the informal sector: Evidence from Brazil”, World Development, 37(5), 992-1003.

Hussmanns, R. (2005), "Measuring the Informal Economy: From Employment in the Informal Sector to Informal Employment”, Policy Integration Department Working Paper No. 53, ILO.

Koenker, R. (2004). “Quantile Regression for Longitudinal Data”, Journal of Multivariate Analysis, 91, 74-89.

Koenker, R. and G. Bassett (1978). “Regression Quantiles”, Econometrica, 46(1), 33-50.

Lee, L. F. (1978). "Unionism and wage rates: a simultaneous equation model with qualitative and limited dependent variables”, International Economic Review, 19, 415-433.

Magnac, T. (1991). “Segmented or Competitive Labor Markets”, Econometrica, 59, 165-187.

Maloney, W. (1999). "Does Informality Imply Segmentation in Urban Labor Markets? Evidence from Sectoral Transitions in Mexico”, World Bank Economic Review, 13, 275-302.

Marcouiller, D., V. R. de Castilla and C. Woodruff (1997). "Formal Measures of the InformalSector Wage Gap in Mexico, El Salvador and Peru", Economic Development and Cultural Change, 45, 367-392.

Mazumdar, D. (1976). “The urban informal sector”, World Development, 4, 655-679.

Mazumdar, D. (1981). The urban labor market income distribution: A study of Malaysia, Oxford University Press, Oxford.

Mincer, J. (1958), “Investment in Human Capital and Personal Income Distribution,” Journal of Political Economy, 66, 197-201.

Mincer, J. (1962), “On-the-Job Training: Costs, Returns, and Some Implications,” Journal of Political Economy, 70, 50-79.

Mincer, J. (1974). Schooling, Experience and Earnings, Columbia University Press, New York.

Nguyen, H. C., C. J. Nordman and F. Roubaud (2011), "Who Suffers the Penalty? A Panel Data Analysis of Earnings Gaps in Vietnam”, Mimeo, DIAL, Paris.

Perry, G., W. Maloney, O. Arias, P. Fajnzylber, A. Mason and J. Saavedra-Chanduvi (2007). Informality: Exit and Exclusion, The World Bank.

Pradhan, M. and A. van Soest (1995). "Formal and Informal Sector Employment in Urban Areas of Bolivia”, Labour Economics, 2, 275-297.

Pratap, S. and E. Quintin (2006). "Are Labor Markets Segmented in Argentina? A Semiparametric Approach”, European Economic Review, 50, 1817-1841.

Roberts, B. R. (1989). "Employment structure life cycle and life chances: Formal and informal sectors in Guadalajara”, in A. Portes, M. Castells, L. A. Benton (Eds.), The Informal Economy: Studies in Advanced and Less Developed Countries, Johns Hopkins University Press, Baltimore. 
Saavedra, J. and A. Chong (1999). "Structural Reform, Institutions and Earnings: Evidence from the Formal and Informal Sectors in Urban Peru”, Journal of Development Studies, 35, 95-116.

Schultz, T. W. (1960). “Capital Formation by Education”, Journal of Political Economy, 68, 571583.

Schultz, T. W. (1961), “Investment in Human Capital”, American Economic Review, 51, 1-17.

Tannuri-Pianto, M. and D. Pianto (2002). "Informal Employment in Brazil - A Choice at the Top and Segmentation at the Bottom: A Quantile Regression Approach", Department of Economics Working Paper No. 236, University of Brasilia.

Tansel, A. (1999). "Formal versus Informal Sector Choice of Wage Earners and Their Wages in Turkey”, Economic Research Forum Working Paper No. 9927.

Tansel, A. (2000). "Wage Earners, Self Employed and Gender in the Informal Sector in Turkey", Policy Research Report on Gender and Development No.24, The World Bank.

Tansel, A. and E. Ö. Kan (2012). "Labor Mobility across the Formal/Informal Divide in Turkey: Evidence from Individual Level Data”, IZA Discussion Papers No. 6271.

Turkish Statistical Institute (TURKSTAT) (2011), Income and Living Conditions Survey Data 2006-2009, Ankara.

Turkish Statistical Institute (TURKSTAT) (2012), Press Release on the Household Labor Force Survey for January 2012, Ankara. 
Table 1: Summary Statistics

\begin{tabular}{|c|c|c|c|c|c|c|c|c|c|c|c|c|}
\hline \multirow[b]{3}{*}{ Variable } & \multicolumn{6}{|c|}{ Formal Employment } & \multicolumn{6}{|c|}{ Informal Employment } \\
\hline & \multicolumn{2}{|c|}{ III employmen } & \multicolumn{2}{|c|}{ Wage Workers } & \multicolumn{2}{|c|}{ Self-employed } & \multicolumn{2}{|c|}{ III employmen } & \multicolumn{2}{|c|}{ Wage Workers } & \multicolumn{2}{|c|}{ Self-employed } \\
\hline & Mean & Sd & Mean & $\mathrm{Sd}$ & Mean & $S d$ & Mean & $S d$ & Mean & $\mathrm{Sd}$ & Mean & $\mathrm{Sd}$ \\
\hline Log hourly earnings & 0.97 & 0.71 & 1.03 & 0.67 & 0.44 & 0.72 & 0.31 & 0.85 & 0.67 & 0.83 & 0.17 & 0.95 \\
\hline Hours worked (pw) & 53.01 & 14.00 & 51.63 & 13.01 & 54.88 & 17.41 & 52.99 & 17.92 & 60.93 & 16.56 & 50.94 & 18.25 \\
\hline Gender & & & & & & & & & & & & \\
\hline Male & 0.82 & 0.38 & 0.80 & 0.40 & 0.81 & 0.39 & 0.81 & 0.39 & 0.96 & 0.20 & 0.82 & 0.39 \\
\hline Female & 0.18 & 0.38 & 0.20 & 0.40 & 0.19 & 0.39 & 0.19 & 0.39 & 0.04 & 0.20 & 0.18 & 0.39 \\
\hline Age & & & & & & & & & & & & \\
\hline Age15to24 & 0.11 & 0.32 & 0.13 & 0.34 & 0.25 & 0.43 & 0.14 & 0.35 & 0.03 & 0.16 & 0.03 & 0.16 \\
\hline Age25to34 & 0.36 & 0.48 & 0.39 & 0.49 & 0.28 & 0.45 & 0.22 & 0.42 & 0.23 & 0.42 & 0.17 & 0.38 \\
\hline Age35to44 & 0.34 & 0.47 & 0.33 & 0.47 & 0.24 & 0.43 & 0.25 & 0.44 & 0.36 & 0.48 & 0.27 & 0.44 \\
\hline Age45to54 & 0.16 & 0.37 & 0.14 & 0.35 & 0.17 & 0.38 & 0.24 & 0.43 & 0.29 & 0.45 & 0.32 & 0.47 \\
\hline Age55to64 & 0.02 & 0.15 & 0.01 & 0.11 & 0.06 & 0.24 & 0.14 & 0.34 & 0.09 & 0.29 & 0.22 & 0.41 \\
\hline Education & & & & & & & & & & & & \\
\hline Illiterate & 0.01 & 0.08 & 0.00 & 0.07 & 0.06 & 0.23 & 0.08 & 0.28 & 0.02 & 0.14 & 0.11 & 0.31 \\
\hline Nograde & 0.01 & 0.12 & 0.01 & 0.11 & 0.07 & 0.26 & 0.08 & 0.28 & 0.03 & 0.17 & 0.10 & 0.29 \\
\hline Primary & 0.34 & 0.47 & 0.29 & 0.46 & 0.53 & 0.50 & 0.57 & 0.50 & 0.61 & 0.49 & 0.61 & 0.49 \\
\hline Secondary & 0.14 & 0.34 & 0.14 & 0.35 & 0.19 & 0.39 & 0.14 & 0.34 & 0.11 & 0.32 & 0.09 & 0.28 \\
\hline High & 0.14 & 0.35 & 0.15 & 0.36 & 0.08 & 0.27 & 0.06 & 0.24 & 0.10 & 0.31 & 0.04 & 0.20 \\
\hline Vocational & 0.14 & 0.35 & 0.15 & 0.36 & 0.05 & 0.23 & 0.05 & 0.21 & 0.08 & 0.26 & 0.04 & 0.19 \\
\hline University & 0.22 & 0.42 & 0.25 & 0.43 & 0.03 & 0.17 & 0.02 & 0.15 & 0.05 & 0.21 & 0.02 & 0.13 \\
\hline Experience & 15.15 & 9.62 & 13.93 & 8.90 & 15.00 & 11.20 & 20.06 & 12.65 & 22.12 & 10.58 & 25.54 & 11.82 \\
\hline Household & & & & & & & & & & & & \\
\hline Single & 0.20 & 0.40 & 0.22 & 0.42 & 0.28 & 0.45 & 0.19 & 0.40 & 0.06 & 0.24 & 0.10 & 0.29 \\
\hline Married & 0.80 & 0.40 & 0.78 & 0.42 & 0.72 & 0.45 & 0.81 & 0.40 & 0.94 & 0.24 & 0.90 & 0.29 \\
\hline nochild & 0.24 & 0.43 & 0.25 & 0.43 & 0.20 & 0.40 & 0.25 & 0.43 & 0.23 & 0.42 & 0.29 & 0.45 \\
\hline child & 0.76 & 0.43 & 0.75 & 0.43 & 0.79 & 0.40 & 0.75 & 0.43 & 0.77 & 0.42 & 0.71 & 0.46 \\
\hline hhead & 0.66 & 0.47 & 0.63 & 0.48 & 0.56 & 0.50 & 0.66 & 0.47 & 0.83 & 0.37 & 0.77 & 0.42 \\
\hline hhsize & 4.26 & 1.74 & 4.18 & 1.65 & 5.15 & 2.46 & 5.08 & 2.49 & 4.72 & 2.11 & 5.00 & 2.53 \\
\hline otherf & 1.00 & 0.00 & 1.00 & 0.00 & 0.23 & 0.42 & 0.19 & 0.40 & 1.00 & 0.00 & 0.16 & 0.37 \\
\hline Sector & & & & & & & & & & & & \\
\hline Agriculture & 0.07 & 0.25 & 0.01 & 0.10 & 0.13 & 0.34 & 0.39 & 0.49 & 0.40 & 0.49 & 0.66 & 0.47 \\
\hline Mining & 0.01 & 0.09 & 0.01 & 0.10 & 0.01 & 0.07 & 0.00 & 0.06 & 0.00 & 0.00 & 0.00 & 0.03 \\
\hline Manufacturing & 0.26 & 0.44 & 0.29 & 0.45 & 0.18 & 0.39 & 0.12 & 0.32 & 0.07 & 0.26 & 0.05 & 0.21 \\
\hline Energy & 0.01 & 0.10 & 0.01 & 0.11 & 0.00 & 0.02 & 0.00 & 0.01 & 0.00 & 0.00 & 0.00 & 0.00 \\
\hline Construction & 0.05 & 0.21 & 0.05 & 0.22 & 0.21 & 0.41 & 0.12 & 0.32 & 0.02 & 0.14 & 0.02 & 0.15 \\
\hline Trade & 0.15 & 0.36 & 0.12 & 0.33 & 0.14 & 0.34 & 0.14 & 0.35 & 0.30 & 0.46 & 0.15 & 0.35 \\
\hline Hotels & 0.04 & 0.19 & 0.04 & 0.19 & 0.07 & 0.26 & 0.05 & 0.21 & 0.05 & 0.21 & 0.02 & 0.14 \\
\hline Transportation & 0.06 & 0.23 & 0.05 & 0.22 & 0.07 & 0.26 & 0.06 & 0.25 & 0.09 & 0.29 & 0.05 & 0.23 \\
\hline Finances & 0.07 & 0.26 & 0.08 & 0.28 & 0.03 & 0.17 & 0.02 & 0.14 & 0.03 & 0.16 & 0.01 & 0.10 \\
\hline PublicAdmin. & 0.11 & 0.32 & 0.13 & 0.34 & 0.03 & 0.18 & 0.02 & 0.13 & 0.00 & 0.00 & 0.00 & 0.00 \\
\hline Education & 0.09 & 0.28 & 0.10 & 0.30 & 0.01 & 0.10 & 0.01 & 0.08 & 0.00 & 0.03 & 0.00 & 0.03 \\
\hline Health & 0.05 & 0.21 & 0.06 & 0.23 & 0.01 & 0.08 & 0.00 & 0.07 & 0.01 & 0.07 & 0.00 & 0.04 \\
\hline OtherServices & 0.04 & 0.19 & 0.04 & 0.20 & 0.11 & 0.31 & 0.07 & 0.26 & 0.03 & 0.16 & 0.03 & 0.18 \\
\hline Occupation & & & & & & & & & & & & \\
\hline Legislators & 0.08 & 0.28 & 0.05 & 0.23 & 0.03 & 0.17 & 0.06 & 0.25 & 0.26 & 0.44 & 0.10 & 0.30 \\
\hline Professionals & 0.13 & 0.33 & 0.14 & 0.35 & 0.01 & 0.12 & 0.01 & 0.10 & 0.03 & 0.16 & 0.01 & 0.08 \\
\hline Technicians & 0.10 & 0.29 & 0.11 & 0.31 & 0.02 & 0.15 & 0.02 & 0.14 & 0.02 & 0.13 & 0.01 & 0.12 \\
\hline Clerks & 0.09 & 0.29 & 0.11 & 0.31 & 0.03 & 0.16 & 0.01 & 0.12 & 0.00 & 0.03 & 0.00 & 0.01 \\
\hline ServiceWorkers & 0.12 & 0.33 & 0.13 & 0.34 & 0.18 & 0.38 & 0.10 & 0.30 & 0.04 & 0.20 & 0.02 & 0.15 \\
\hline SkilledAgricultural & 0.06 & 0.24 & 0.00 & 0.07 & 0.01 & 0.11 & 0.32 & 0.47 & 0.40 & 0.49 & 0.66 & 0.47 \\
\hline Craftsmen & 0.14 & 0.35 & 0.15 & 0.36 & 0.29 & 0.45 & 0.19 & 0.39 & 0.12 & 0.33 & 0.08 & 0.27 \\
\hline PlantOperators & 0.15 & 0.36 & 0.16 & 0.37 & 0.12 & 0.32 & 0.09 & 0.28 & 0.11 & 0.31 & 0.06 & 0.23 \\
\hline ElementaryOperation & 0.12 & 0.32 & 0.13 & 0.34 & 0.31 & 0.46 & 0.19 & 0.39 & 0.02 & 0.14 & 0.06 & 0.24 \\
\hline Firm Size & & & & & & & & & & & & \\
\hline small & 0.34 & 0.47 & 0.22 & 0.42 & 0.74 & 0.44 & 0.86 & 0.34 & 1.00 & 0.03 & 1.00 & 0.03 \\
\hline medium & 0.25 & 0.44 & 0.30 & 0.46 & 0.20 & 0.40 & 0.10 & 0.30 & 0.00 & 0.02 & 0.00 & 0.02 \\
\hline large & 0.41 & 0.49 & 0.48 & 0.50 & 0.06 & 0.24 & 0.03 & 0.18 & 0.00 & 0.00 & 0.00 & 0.02 \\
\hline Job Type & & & & & & & & & & & & \\
\hline fulltime & 0.98 & 0.13 & 0.99 & 0.12 & 0.89 & 0.32 & 0.87 & 0.33 & 0.97 & 0.17 & 0.86 & 0.35 \\
\hline parttime & 0.02 & 0.12 & 0.01 & 0.11 & 0.10 & 0.30 & 0.12 & 0.32 & 0.03 & 0.17 & 0.14 & 0.34 \\
\hline Year & & & & & & & & & & & & \\
\hline 2006 & 0.17 & 0.38 & 0.17 & 0.38 & 0.21 & 0.41 & 0.21 & 0.41 & 0.17 & 0.38 & 0.21 & 0.40 \\
\hline 2007 & 0.28 & 0.45 & 0.28 & 0.45 & 0.31 & 0.46 & 0.31 & 0.46 & 0.27 & 0.45 & 0.30 & 0.46 \\
\hline 2008 & 0.32 & 0.47 & 0.32 & 0.47 & 0.29 & 0.45 & 0.28 & 0.45 & 0.33 & 0.47 & 0.28 & 0.45 \\
\hline 2009 & 0.22 & 0.42 & 0.22 & 0.42 & 0.19 & 0.39 & 0.20 & 0.40 & 0.23 & 0.42 & 0.22 & 0.41 \\
\hline \#observations & 173 & & 148 & 304 & 63 & 50 & 122 & 217 & & 93 & & 67 \\
\hline
\end{tabular}


Table 2a: Pooled OLS Mincer Earnings Regressions (Across Formal/Informal Employment)

\begin{tabular}{|c|c|c|c|c|c|c|c|c|c|}
\hline \multirow[b]{4}{*}{ Informal } & \multicolumn{3}{|c|}{ ALL } & \multicolumn{3}{|c|}{ M ALE } & \multicolumn{3}{|c|}{ FEM ALE } \\
\hline & (1) & (2) & (3) & (4) & (5) & (6) & (7) & (8) & (9) \\
\hline & \multicolumn{3}{|c|}{ Pooled OLS Pooled OLS Pooled OLS } & \multicolumn{3}{|c|}{ Pooled OLS Pooled OLS Pooled OLS } & \multicolumn{3}{|c|}{ Pooled OLS Pooled OLS Pooled OLS } \\
\hline & $-0.539 * * *$ & $-0.318^{* * *}$ & $-0.215^{* * *}$ & $-0.505^{* * *}$ & $-0.256 * * *$ & $-0.196 * * *$ & $-0.707 * * *$ & $-0.456^{* * *}$ & $-0.181^{* * *}$ \\
\hline Hourspw & & $-0.0158^{* * *}$ & $-0.0158 * * *$ & & $-0.0166^{* * *}$ & $-0.0155^{* * *}$ & & $-0.0139 * * *$ & $-0.0190 * * *$ \\
\hline Exper & & $0.0268^{* * *}$ & $0.0237 * * *$ & & $0.0284 * * *$ & $0.0265^{* * *}$ & & $0.0184 * *$ & $0.0162 * *$ \\
\hline Expersq & & $-0.000537 * * *$ & $-0.000502 * * *$ & & $-0.000584 * * *$ & $0.000562 * * *$ & & -0.000375 & -0.000358 \\
\hline Female & & $-0.0850 * * *$ & $-0.0846^{* * *}$ & & 0 & 0 & & 0 & 0 \\
\hline age25to44 & & 0.0227 & 0.0207 & & 0.00399 & -0.00140 & & $0.0992^{*}$ & $0.0875^{*}$ \\
\hline age45to64 & & 0.0276 & 0.0152 & & 0.00978 & -0.00917 & & 0.139 & 0.0903 \\
\hline Illiterate & & $-0.170^{* *}$ & $-0.119^{*}$ & & $-0.173 * * *$ & $-0.102 *$ & & -0.130 & -0.0519 \\
\hline None & & $-0.0752^{*}$ & $-0.0712^{*}$ & & $-0.0749 *$ & $-0.0674^{*}$ & & 0.00164 & -0.000912 \\
\hline Secondary & & $0.0774 * * *$ & $0.0531^{* * *}$ & & $0.0758^{* * *}$ & $0.0593^{* * *}$ & & 0.0852 & 0.0953 \\
\hline High & & $0.257 * * *$ & $0.180^{* * *}$ & & $0.251^{* * *}$ & $0.188^{* * *}$ & & $0.288^{* * *}$ & $0.206^{* * *}$ \\
\hline Vocational & & $0.279 * * *$ & $0.188^{* * *}$ & & $0.269^{* * *}$ & $0.192 * * *$ & & $0.322 * * *$ & $0.192 * * *$ \\
\hline University & & $0.679 * * *$ & $0.433^{* * *}$ & & $0.640^{* * *}$ & $0.432 * * *$ & & $0.745 * * *$ & $0.420 * * *$ \\
\hline student & & -0.235 & -0.537 & & -0.304 & -0.541 & & 0 & 0 \\
\hline Married & & $0.0377^{*}$ & 0.0260 & & $0.0704^{* * *}$ & $0.0576^{* *}$ & & -0.0301 & -0.0377 \\
\hline hhead & & $0.116^{* * *}$ & $0.102 * * *$ & & $0.104 * * *$ & $0.0907^{* * *}$ & & $0.105^{*}$ & 0.0667 \\
\hline child & & 0.0257 & $0.0360 * *$ & & 0.0174 & 0.0276 & & $0.111^{* *}$ & $0.0764^{*}$ \\
\hline hhsize & & $-0.00651^{*}$ & $-0.00924 * *$ & & $-0.00611^{*}$ & $-0.00719^{*}$ & & $-0.0375 * * *$ & $-0.0295^{* *}$ \\
\hline otherf & & -0.0256 & -0.00425 & & 0.0113 & 0.0152 & & -0.00342 & 0.00478 \\
\hline Mining & & & 0.0352 & & & 0.00225 & & & 0.120 \\
\hline Energy & & & $0.268^{* * *}$ & & & $0.274^{* * *}$ & & & -0.664 \\
\hline Construction & & & $0.209^{* * *}$ & & & $0.136^{* * *}$ & & & 0.120 \\
\hline Trade & & & $0.0644^{* * *}$ & & & 0.0123 & & & $0.110^{*}$ \\
\hline Hotels & & & 0.0431 & & & -0.0245 & & & $0.227 * *$ \\
\hline Transportation & & & $0.142 * * *$ & & & $0.1000^{* * *}$ & & & $0.244 * *$ \\
\hline Finances & & & 0.00251 & & & $-0.0583^{*}$ & & & $0.102^{*}$ \\
\hline PublicAdminis & & & $0.0589 * *$ & & & 0.0304 & & & $0.118 *$ \\
\hline Education & & & $-0.0579 *$ & & & $-0.105^{* * *}$ & & & -0.0478 \\
\hline Health & & & $0.119^{* * *}$ & & & $0.105^{* *}$ & & & $0.122^{*}$ \\
\hline OtherServices & & & $0.0512 *$ & & & $-0.0642^{*}$ & & & $0.244 * * *$ \\
\hline Legislators & & & -0.0492 & & & $-0.0738^{*}$ & & & 0.123 \\
\hline Technicians & & & $-0.203^{* * *}$ & & & $-0.211^{* * *}$ & & & $-0.216 * * *$ \\
\hline Clerks & & & $-0.328 * * *$ & & & $-0.334 * * *$ & & & $-0.359 * * *$ \\
\hline ServiceWorkeı & & & $-0.349 * * *$ & & & $-0.359 * * *$ & & & $-0.323 * * *$ \\
\hline SkilledAgricul & & & $-0.373 * * *$ & & & $-0.359 * * *$ & & & $-0.350 * * *$ \\
\hline Craftsmen & & & $-0.373 * * *$ & & & $-0.339 * * *$ & & & $-0.913 * * *$ \\
\hline PlantOperators & & & $-0.325 * * *$ & & & $-0.350 * * *$ & & & $-0.261 * * *$ \\
\hline ElementaryOp & & & $-0.427 * * *$ & & & $-0.459 * * *$ & & & $-0.344 * * *$ \\
\hline medium & & & $0.122 * * *$ & & & $0.0833 * * *$ & & & $0.284 * * *$ \\
\hline large & & & $0.259 * * *$ & & & $0.230^{* * *}$ & & & $0.379^{* * *}$ \\
\hline fulltime & & & 0.0716 & & & -0.0362 & & & 0.494 \\
\hline parttime & & & -0.000814 & & & 0.0655 & & & 0.275 \\
\hline y2007 & -0.00877 & 0.00263 & 0.00501 & -0.00178 & 0.00886 & 0.0101 & -0.0471 & -0.0298 & -0.00884 \\
\hline y2008 & -0.0128 & -0.00351 & 0.00340 & -0.00604 & 0.00649 & 0.0121 & -0.0499 & -0.0455 & -0.0215 \\
\hline y2009 & $0.0446^{* *}$ & $0.0300^{*}$ & $0.0418 * * *$ & $0.0472 * *$ & $0.0391 * *$ & $0.0497^{* * *}$ & 0.0219 & -0.00329 & 0.0129 \\
\hline _cons & $1.003 * * *$ & $1.280 * * *$ & $1.408^{* * *}$ & $0.984^{* * *}$ & $1.271^{* * *}$ & $1.503^{* * *}$ & $1.091^{* * *}$ & $1.219 * * *$ & $1.037 * *$ \\
\hline $\mathrm{N}$ & 23668 & 23667 & 23656 & 19414 & 19413 & 19403 & 4254 & 4254 & 4253 \\
\hline
\end{tabular}


Table 2b: Pooled OLS Mincer Earnings Regressions (Across Formal-Salaried/Informal Salaried/Formal Selfemployed/Informal Self-employed employment)

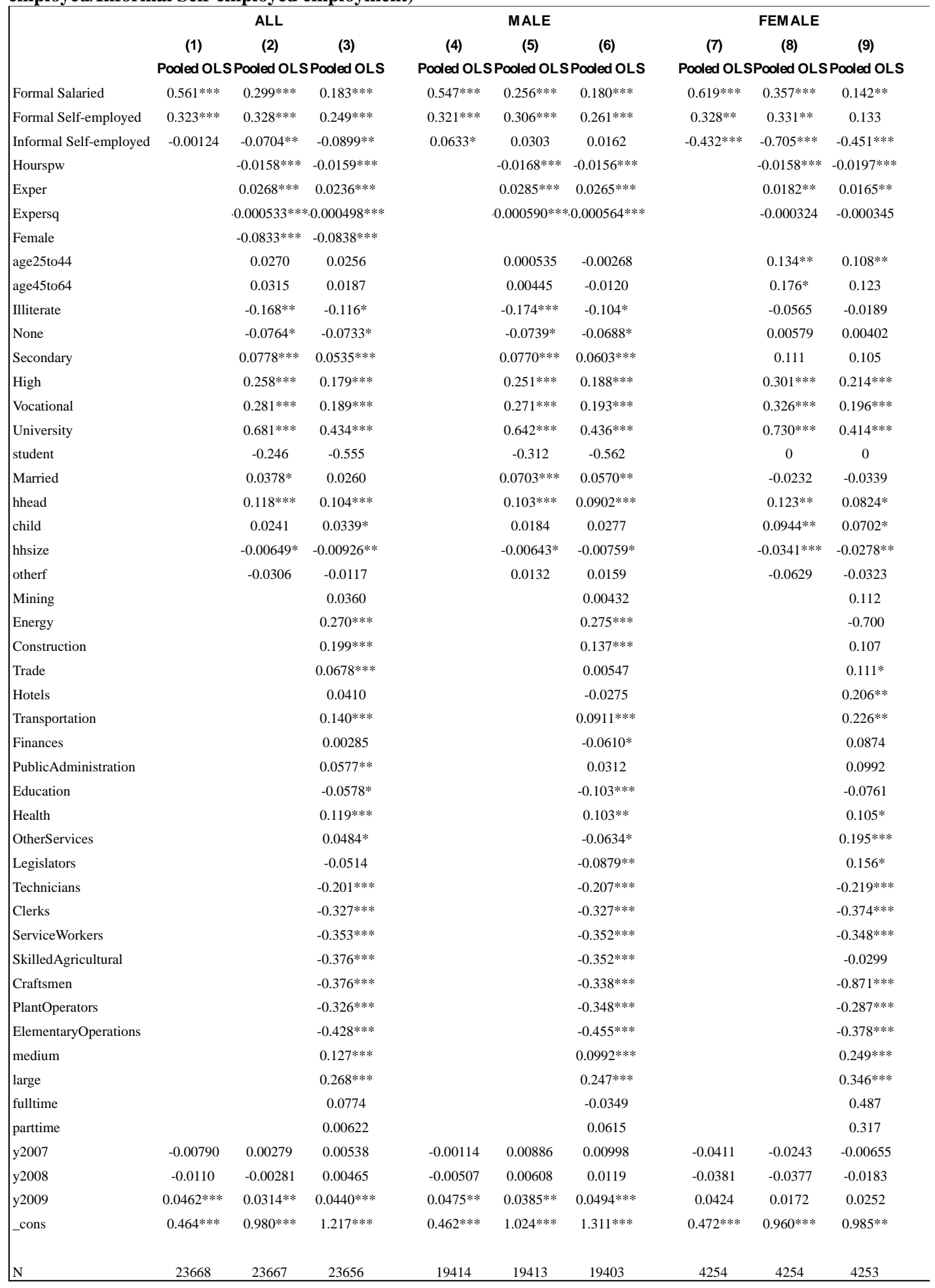


Table 3a: Pooled Quantile Mincer Earnings Regressions (Across Formal/Informal Employment)

\begin{tabular}{|c|c|c|c|c|c|c|c|}
\hline \multicolumn{8}{|c|}{ ALL } \\
\hline & 5th quantile & 10th quantile & 25th quantile & 50th quantile & 75th quantile & 90th quantile & 95th quantile \\
\hline Informal & $-0.593 * * *$ & $-0.452 * * *$ & $-0.277^{* * *}$ & $-0.167 * * *$ & $-0.0892 * * *$ & 0.000798 & $0.129 * *$ \\
\hline Hourspw & $-0.0156^{* * *}$ & $-0.0162 * * *$ & $-0.0165 * * *$ & $-0.0166 * * *$ & $-0.0168 * * *$ & $-0.0165 * * *$ & $-0.0159 * * *$ \\
\hline Exper & $0.0321^{* * *}$ & $0.0275^{* * *}$ & $0.0254 * * *$ & $0.0242 * * *$ & $0.0251 * * *$ & $0.0175^{* * *}$ & $0.00803^{*}$ \\
\hline Expersq & $-0.000739 * * *$ & $-0.000636 * * *$ & $-0.000571^{* * *}$ & $-0.000519 * * *$ & $-0.000523^{* * *}$ & $-0.000299 * * *$ & -0.00000231 \\
\hline Female & -0.0450 & $-0.0673 *$ & $-0.0660 * * *$ & $-0.0686^{* * *}$ & $-0.0429 * * *$ & $-0.0404 *$ & -0.0117 \\
\hline age25to44 & 0.0314 & -0.00346 & 0.0172 & $0.0541^{* * *}$ & $0.0653 * * *$ & -0.0306 & $-0.111 * *$ \\
\hline age45to64 & 0.0360 & -0.0101 & 0.0134 & $0.0444 *$ & $0.0657 * *$ & -0.00638 & $-0.138 * * *$ \\
\hline Illiterate & -0.300 & -0.160 & $-0.103 * *$ & $-0.106 *$ & -0.0915 & -0.00133 & -0.0815 \\
\hline None & 0.0257 & -0.0327 & -0.0436 & -0.0418 & $-0.0804 * *$ & $-0.172 * * *$ & $-0.159 * *$ \\
\hline Secondary & 0.0227 & $0.0438^{*}$ & $0.0446^{* * *}$ & $0.0693^{* * *}$ & $0.0743 * * *$ & $0.0927 * * *$ & $0.0806^{* *}$ \\
\hline High & $0.167 * * *$ & $0.156^{* * *}$ & $0.161^{* * *}$ & $0.187 * * *$ & $0.179 * * *$ & $0.199 * * *$ & $0.200 * * *$ \\
\hline Vocational & $0.121^{* *}$ & $0.133^{* * *}$ & $0.167^{* * *}$ & $0.195^{* * *}$ & $0.197 * * *$ & $0.196^{* * *}$ & $0.214^{* * *}$ \\
\hline University & $0.376^{* * *}$ & $0.389 * * *$ & $0.399 * * *$ & $0.431 * * *$ & $0.426 * * *$ & $0.440^{* * *}$ & $0.465^{* * *}$ \\
\hline student & 0.155 & -0.239 & -0.751 & 0.107 & -0.286 & -0.971 & -1.559 \\
\hline Married & 0.0410 & $0.0555 *$ & $0.0595^{* * *}$ & $0.0425^{* * *}$ & 0.0217 & 0.0317 & 0.0327 \\
\hline hhead & $0.139 * * *$ & $0.108 * * *$ & $0.0885^{* * *}$ & $0.0682 * * *$ & $0.0984 * * *$ & $0.107 * * *$ & $0.121^{* * *}$ \\
\hline child & 0.0328 & $0.0382 *$ & $0.0249 *$ & $0.0302^{* *}$ & 0.0187 & 0.0228 & 0.0451 \\
\hline hhsize & -0.00137 & $-0.00917^{* *}$ & $-0.00929 * * *$ & $-0.0115^{* * *}$ & $-0.00912 * *$ & $-0.0124 * * *$ & $-0.0179 * *$ \\
\hline otherf & $-0.208 * * *$ & $-0.144 * * *$ & $-0.0466^{*}$ & $0.0326^{*}$ & $0.0700^{* *}$ & $0.119 * *$ & $0.206^{* * *}$ \\
\hline Mining & -0.0550 & -0.0381 & -0.0211 & 0.0313 & 0.108 & $0.161^{* * *}$ & 0.0835 \\
\hline Energy & $0.191^{*}$ & $0.213^{* *}$ & $0.288 * * *$ & $0.336^{* * *}$ & $0.318 * * *$ & $0.218^{* * *}$ & $0.146^{* *}$ \\
\hline Construction & $0.177 * * *$ & $0.156 * * *$ & $0.135^{* * *}$ & $0.164^{* * *}$ & $0.194 * * *$ & $0.154 * * *$ & $0.115^{* * *}$ \\
\hline Trade & $0.0797 * *$ & 0.0337 & -0.00379 & 0.00986 & $0.0481 * * *$ & $0.0651^{* *}$ & 0.0668 \\
\hline Hotels & 0.0388 & 0.0275 & 0.00102 & 0.0324 & 0.0205 & 0.0388 & 0.0672 \\
\hline Transportation & $0.0978 * *$ & $0.0842 * * *$ & $0.0678^{* * *}$ & $0.106^{* * *}$ & $0.188^{* * *}$ & $0.170^{* * *}$ & $0.134 * * *$ \\
\hline Finances & $-0.0821^{*}$ & $-0.0796 * *$ & $-0.115^{* * *}$ & $-0.0457 * *$ & $0.0880 * *$ & $0.139 * *$ & $0.145^{* * *}$ \\
\hline PublicAdministra & $0.156^{* * *}$ & $0.126 * * *$ & $0.133^{* * *}$ & $0.114 * * *$ & $0.0464 * * *$ & $-0.0533^{*}$ & $-0.101 * * *$ \\
\hline Education & $0.156^{* * *}$ & $0.106^{* * *}$ & $0.0616^{* * *}$ & -0.00115 & $-0.155^{* * *}$ & $-0.346^{* * *}$ & $-0.460^{* * *}$ \\
\hline Health & $0.0817 *$ & $0.0735^{* * *}$ & $0.112 * * *$ & $0.133^{* * *}$ & $0.0859 * * *$ & 0.0589 & 0.0712 \\
\hline OtherServices & 0.0534 & 0.00989 & 0.00317 & -0.00157 & 0.00394 & -0.0476 & $-0.0968^{*}$ \\
\hline Legislators & $-0.344 * * *$ & $-0.302 * * *$ & $-0.142 * * *$ & $0.0454^{*}$ & $0.117 * * *$ & $0.0959 * * *$ & $0.118^{* *}$ \\
\hline Technicians & $-0.219 * * *$ & $-0.202 * * *$ & $-0.185 * * *$ & $-0.143 * * *$ & $-0.167 * * *$ & $-0.244 * * *$ & $-0.233 * * *$ \\
\hline Clerks & $-0.278 * * *$ & $-0.317 * * *$ & $-0.309 * * *$ & $-0.286 * * *$ & $-0.335^{* * *}$ & $-0.403^{* * *}$ & $-0.355^{* * *}$ \\
\hline ServiceWorkers & $-0.315 * * *$ & $-0.336 * * *$ & $-0.324 * * *$ & $-0.292 * * *$ & $-0.337 * * *$ & $-0.400 * * *$ & $-0.409 * * *$ \\
\hline SkilledAgricultur & -0.387 & $-0.404 * *$ & $-0.288 * * *$ & $-0.272 * * *$ & $-0.331 * * *$ & $-0.562 * * *$ & $-0.531 * * *$ \\
\hline Craftsmen & $-0.397 * * *$ & $-0.382 * * *$ & $-0.333 * * *$ & $-0.282 * * *$ & $-0.321 * * *$ & $-0.383^{* * *}$ & $-0.405^{* * *}$ \\
\hline PlantOperators & $-0.303^{* * *}$ & $-0.331 * * *$ & $-0.312 * * *$ & $-0.271 * * *$ & $-0.330 * * *$ & $-0.401^{* * *}$ & $-0.387 * * *$ \\
\hline ElementaryOpera & a $-0.416^{* * *}$ & $-0.435 * * *$ & $-0.423 * * *$ & $-0.388 * * *$ & $-0.422 * * *$ & $-0.455^{* * *}$ & $-0.403 * * *$ \\
\hline medium & $0.170 * * *$ & $0.127 * * *$ & $0.0988 * * *$ & $0.0901 * * *$ & $0.0954 * * *$ & $0.0601 * *$ & 0.0465 \\
\hline large & $0.316^{* * *}$ & $0.266^{* * *}$ & $0.212^{* * *}$ & $0.200^{* * *}$ & $0.224 * * *$ & $0.229 * * *$ & $0.218^{* * *}$ \\
\hline fulltime & 0.225 & $0.206 *$ & 0.0838 & 0.0732 & 0.0174 & -0.252 & -0.478 \\
\hline parttime & $-0.862^{*}$ & $-0.503 * * *$ & -0.126 & 0.108 & 0.135 & -0.0264 & -0.105 \\
\hline _cons & 0.642 & $0.946^{* * *}$ & $1.235^{* * *}$ & $1.362 * * *$ & $1.667 * * *$ & $2.382 * * *$ & $2.815^{* * *}$ \\
\hline $\mathrm{N}$ & 23656 & & & & & & \\
\hline
\end{tabular}


Table 3b: Pooled Quantile Mincer Earnings Regressions (Across Formal/Informal Employment)

\begin{tabular}{|c|c|c|c|c|c|c|c|}
\hline \multicolumn{8}{|c|}{ MALE } \\
\hline & 5th quantile & 10th quantile & 25th quantile & 50th quantile & 75th quantile & 90th quantile & 95th quantile \\
\hline informal & $-0.476 * * *$ & $-0.404 * * *$ & $-0.232 * * *$ & $-0.161 * * *$ & $-0.137 * * *$ & -0.0359 & 0.0359 \\
\hline Hourspw & $-0.0151^{* * *}$ & $-0.0161 * * *$ & $-0.0168 * * *$ & $-0.0164 * * *$ & $-0.0159 * * *$ & $-0.0157 * * *$ & $-0.0146 * * *$ \\
\hline Exper & $0.0301 * * *$ & $0.0271^{* * *}$ & $0.0257 * * *$ & $0.0254 * * *$ & $0.0282^{* * *}$ & $0.0229 * * *$ & $0.0164 * *$ \\
\hline Expersq & $-0.000697 * * *$ & $-0.000644 * * *$ & $-0.000588 * * *$ & $-0.000533 * * *$ & $-0.000587 * * *$ & $-0.000400 * * *$ & -0.000179 \\
\hline \multicolumn{8}{|l|}{ Female } \\
\hline age25to44 & 0.0597 & 0.0197 & 0.0203 & $0.0362 *$ & 0.0214 & $-0.102 * *$ & $-0.177 * *$ \\
\hline age45to64 & 0.0459 & 0.0107 & 0.0187 & 0.0239 & 0.0254 & $-0.0921^{*}$ & $-0.195 * *$ \\
\hline Illiterate & -0.215 & -0.131 & $-0.0829 *$ & $-0.103^{* *}$ & $-0.105^{*}$ & -0.0209 & -0.143 \\
\hline None & 0.0338 & -0.00732 & $-0.0554 *$ & $-0.0660 * *$ & $-0.0902 * *$ & $-0.162 * *$ & $-0.158 * *$ \\
\hline Secondary & 0.00323 & $0.0414 * *$ & $0.0499 * * *$ & $0.0802 * * *$ & $0.0820^{* * *}$ & $0.0836^{* * *}$ & $0.0943^{* *}$ \\
\hline High & $0.162^{* * *}$ & $0.157 * * *$ & $0.165^{* * *}$ & $0.194 * * *$ & $0.183^{* * *}$ & $0.177^{* * *}$ & $0.194 * * *$ \\
\hline Vocational & $0.0947 * *$ & $0.116^{* * *}$ & $0.171^{* * *}$ & $0.201 * * *$ & $0.206 * * *$ & $0.201^{* * *}$ & $0.237 * * *$ \\
\hline University & $0.372 * * *$ & $0.388 * * *$ & $0.409 * * *$ & $0.434 * * *$ & $0.410^{* * *}$ & $0.414 * * *$ & $0.503 * * *$ \\
\hline student & -0.0654 & -0.280 & -0.819 & 0.134 & -0.223 & -0.935 & -1.466 \\
\hline Married & 0.111 & $0.109 * * *$ & $0.0603^{* * *}$ & $0.0564^{* * *}$ & 0.0264 & $0.0591^{*}$ & 0.0206 \\
\hline hhead & $0.113^{* * *}$ & $0.0682^{* * *}$ & $0.0957^{* * *}$ & $0.0678^{* * *}$ & $0.101^{* * *}$ & $0.0978^{* * *}$ & $0.0940 * *$ \\
\hline child & 0.0526 & $0.0402 *$ & 0.0147 & $0.0309 * *$ & 0.000649 & -0.000191 & 0.0321 \\
\hline hhsize & -0.00487 & $-0.00881 * *$ & $-0.00591 * *$ & $-0.00976 * * *$ & -0.00503 & $-0.00983 * *$ & -0.0111 \\
\hline otherf & $-0.123^{*}$ & $-0.127 * * *$ & -0.0115 & $0.0386^{* *}$ & 0.0409 & $0.132^{* *}$ & $0.162 *$ \\
\hline Mining & -0.0512 & -0.0386 & -0.0459 & 0.0147 & 0.112 & $0.157 * * *$ & 0.0703 \\
\hline Energy & $0.189 * *$ & $0.222 * * *$ & $0.285^{* * *}$ & $0.368 * * *$ & $0.291 * * *$ & $0.191^{*}$ & 0.174 \\
\hline Construction & 0.0643 & $0.0970 * * *$ & $0.101^{* * *}$ & $0.139 * * *$ & $0.175^{* * *}$ & $0.162 * * *$ & $0.154^{* * *}$ \\
\hline Trade & 0.00794 & -0.00581 & $-0.0289 *$ & -0.00671 & 0.0188 & $0.0726 * *$ & $0.0924 * *$ \\
\hline Hotels & 0.0207 & -0.0186 & -0.0390 & -0.00580 & -0.0140 & -0.000785 & 0.0402 \\
\hline Transportation & 0.0385 & $0.0436 *$ & $0.0447 * *$ & $0.0876^{* * *}$ & $0.152 * * *$ & $0.178^{* * *}$ & $0.191 * * *$ \\
\hline Finances & $-0.144 * * *$ & $-0.136^{* * *}$ & $-0.150 * * *$ & $-0.0833 * * *$ & 0.0708 & $0.164^{* * *}$ & $0.186^{* * *}$ \\
\hline PublicAdministra & $0.111^{* *}$ & $0.0946^{* * *}$ & $0.113^{* * *}$ & $0.0969 * * *$ & $0.0277 *$ & $-0.0498 *$ & $-0.0746 *$ \\
\hline Education & $0.0942 *$ & $0.0851^{* * *}$ & 0.0424 & -0.0171 & $-0.164 * * *$ & $-0.327 * * *$ & $-0.421^{* * *}$ \\
\hline Health & 0.0253 & 0.0267 & $0.136 * * *$ & $0.157 * * *$ & $0.115^{* * *}$ & $0.0651^{*}$ & 0.149 \\
\hline OtherServices & -0.0485 & $-0.0703 * *$ & $-0.0638 * * *$ & $-0.0521 * *$ & $-0.0510 * *$ & $-0.0816^{*}$ & $-0.0889 *$ \\
\hline Legislators & $-0.409 * * *$ & $-0.350 * * *$ & $-0.159 * * *$ & 0.0350 & $0.0952^{* * *}$ & 0.0664 & $0.141^{*}$ \\
\hline Technicians & $-0.293 * * *$ & $-0.226^{* * *}$ & $-0.190 * * *$ & $-0.133 * * *$ & $-0.150 * * *$ & $-0.221 * * *$ & $-0.199 * *$ \\
\hline Clerks & $-0.313 * * *$ & $-0.322 * * *$ & $-0.294^{* * *}$ & $-0.273 * * *$ & $-0.331^{* * *}$ & $-0.439 * * *$ & $-0.380 * * *$ \\
\hline ServiceWorkers & $-0.372 * * *$ & $-0.358 * * *$ & $-0.324 * * *$ & $-0.280 * * *$ & $-0.328 * * *$ & $-0.419 * * *$ & $-0.386 * * *$ \\
\hline SkilledAgricultur & -0.397 & $-0.431^{* * *}$ & $-0.323 * * *$ & $-0.249 * * *$ & $-0.326^{* * *}$ & $-0.498 * * *$ & $-0.518^{* * *}$ \\
\hline Craftsmen & $-0.371 * * *$ & $-0.349 * * *$ & $-0.309 * * *$ & $-0.262 * * *$ & $-0.314^{* * *}$ & $-0.393 * * *$ & $-0.373 * * *$ \\
\hline PlantOperators & $-0.353^{* * *}$ & $-0.348^{* * *}$ & $-0.312^{* * *}$ & $-0.275^{* * *}$ & $-0.333 * * *$ & $-0.425^{* * *}$ & $-0.374 * * *$ \\
\hline ElementaryOpera & a $-0.488 * * *$ & $-0.459 * * *$ & $-0.438 * * *$ & $-0.393 * * *$ & $-0.426 * * *$ & $-0.470 * * *$ & $-0.397 * * *$ \\
\hline medium & $0.157 * * *$ & $0.103^{* * *}$ & $0.0756^{* * *}$ & $0.0663^{* * *}$ & $0.0589 * * *$ & $0.0499 * *$ & 0.0379 \\
\hline large & $0.284^{* * *}$ & $0.239 * * *$ & $0.194 * * *$ & $0.194 * * *$ & $0.217 * * *$ & $0.232 * * *$ & $0.226^{* * *}$ \\
\hline fulltime & -0.0117 & 0.108 & -0.00405 & 0.0517 & -0.0202 & -0.276 & -0.484 \\
\hline parttime & -0.00345 & 0.0526 & -0.0492 & 0.141 & 0.115 & -0.0399 & -0.124 \\
\hline _cons & $0.809 * * *$ & $1.043^{* * *}$ & $1.307 * * *$ & $1.368 * * *$ & $1.721^{* * *}$ & $2.385^{* * *}$ & $2.759 * * *$ \\
\hline $\mathrm{N}$ & 19403 & & & & & & 19403 \\
\hline
\end{tabular}


Table 3c: Pooled Quantile Mincer Earnings Regressions (Across Formal/Informal Employment)

\begin{tabular}{|c|c|c|c|c|c|c|c|}
\hline \multicolumn{8}{|c|}{ FEM ALE } \\
\hline & 5th quantile & 10th quantile & 25th quantile & 50th quantile & 75th quantile & 90th quantile & 95th quantile \\
\hline informal & $-0.450 * * *$ & $-0.435 * * *$ & $-0.300 * * *$ & $-0.167 * * *$ & -0.0462 & 0.151 & $0.351^{* *}$ \\
\hline Hourspw & $-0.0178^{* * *}$ & $-0.0172 * * *$ & $-0.0179 * * *$ & $-0.0182 * * *$ & $-0.0208 * * *$ & $-0.0241 * * *$ & $-0.0208 * * *$ \\
\hline Exper & $0.0415^{* * *}$ & $0.0268 * * *$ & $0.0223^{* * *}$ & $0.0199 * * *$ & $0.0127 * *$ & 0.0053 & -0.0199 \\
\hline Expersq & $-0.000991^{* *}$ & $-0.000549 * *$ & $-0.000491 * * *$ & $-0.000481^{* *}$ & -0.000205 & $-2.77 \mathrm{E}-05$ & 0.000577 \\
\hline \multicolumn{8}{|l|}{ Female } \\
\hline age25to44 & 0.0571 & $0.0662 *$ & $0.0833^{*}$ & $0.0886 * *$ & $0.0926 * * *$ & $0.127 * * *$ & $0.193^{*}$ \\
\hline age45to64 & -0.0339 & 0.0175 & 0.0317 & 0.0766 & 0.0667 & 0.0963 & 0.18 \\
\hline Illiterate & 0.023 & -0.165 & -0.155 & -0.0508 & -0.0306 & 0.000268 & 0.0821 \\
\hline None & -0.14 & -0.019 & 0.073 & 0.0497 & 0.0322 & -0.129 & $-0.319^{*}$ \\
\hline Secondary & 0.113 & 0.0587 & 0.0424 & $0.0945^{* * *}$ & 0.0378 & 0.0828 & -0.0675 \\
\hline High & $0.234 * * *$ & $0.176^{* * *}$ & $0.186^{* * *}$ & $0.196 * * *$ & $0.232 * * *$ & $0.343^{* * *}$ & $0.319 * * *$ \\
\hline Vocational & $0.221^{* * *}$ & $0.165^{* * *}$ & $0.197 * * *$ & $0.168^{* * *}$ & $0.181^{* * *}$ & $0.273^{* * *}$ & $0.171^{* *}$ \\
\hline University & $0.411^{* * *}$ & $0.346^{* * *}$ & $0.365^{* * *}$ & $0.366^{* * *}$ & $0.453 * * *$ & $0.554 * * *$ & $0.499 * * *$ \\
\hline \multicolumn{8}{|l|}{ student } \\
\hline Married & -0.0178 & 0.0238 & 0.0422 & 0.00148 & -0.0119 & -0.0298 & -0.0574 \\
\hline hhead & 0.0831 & $0.0796 *$ & $0.0628^{*}$ & 0.0406 & 0.0508 & $0.141^{* * *}$ & $0.168^{*}$ \\
\hline child & -0.015 & 0.0356 & 0.026 & 0.0212 & 0.0296 & $0.111^{* *}$ & $0.241^{* * *}$ \\
\hline hhsize & -0.0169 & $-0.0262 *$ & $-0.0161 *$ & $-0.0226 * * *$ & $-0.0238 * * *$ & -0.0214 & $-0.0559 * * *$ \\
\hline otherf & -0.0116 & -0.097 & -0.0588 & 0.0509 & 0.055 & 0.0634 & 0.181 \\
\hline Mining & 0.524 & 0.395 & 0.177 & -0.0386 & 0.0484 & -0.336 & $-0.698 * * *$ \\
\hline Energy & -3.227 & -3.371 & 0.149 & -0.0431 & -0.182 & $-0.531 * *$ & $-0.889 * * *$ \\
\hline Construction & $0.299 *$ & 0.0632 & 0.0625 & 0.0637 & 0.0535 & 0.253 & -0.241 \\
\hline Trade & 0.00586 & 0.0573 & $0.0821^{*}$ & 0.0281 & 0.0442 & 0.0174 & -0.116 \\
\hline Hotels & -0.0113 & -0.0378 & 0.0838 & $0.172 * *$ & $0.161^{*}$ & 0.168 & 0.307 \\
\hline Transportation & $0.304 * *$ & $0.250 * * *$ & $0.188^{*}$ & $0.268^{* *}$ & $0.261^{* *}$ & -0.0471 & $-0.291 * *$ \\
\hline Finances & 0.0121 & -0.00359 & 0.00149 & 0.0503 & 0.0685 & -0.0428 & -0.127 \\
\hline PublicAdministra & $0.234^{* *}$ & $0.178^{* *}$ & $0.172 * * *$ & $0.151^{* *}$ & $0.0848^{*}$ & -0.161 & $-0.411 * * *$ \\
\hline Education & 0.131 & 0.117 & 0.0603 & -0.0315 & $-0.173^{* *}$ & $-0.476 * * *$ & $-0.688 * * *$ \\
\hline Health & 0.0847 & 0.0953 & $0.122 * *$ & $0.101^{*}$ & 0.098 & -0.00174 & $-0.220^{*}$ \\
\hline OtherServices & $0.156^{*}$ & $0.141^{*}$ & $0.165^{* * *}$ & $0.166^{* * *}$ & 0.108 & -0.0854 & $-0.314 * *$ \\
\hline Legislators & -0.119 & -0.0596 & -0.0351 & 0.0935 & $0.320 * * *$ & $0.361 * * *$ & $0.242 *$ \\
\hline Technicians & -0.068 & $-0.164 * *$ & $-0.203^{* * *}$ & $-0.228 * * *$ & $-0.191 * * *$ & $-0.304 * * *$ & $-0.257 * *$ \\
\hline Clerks & $-0.211 * * *$ & $-0.314 * * *$ & $-0.382 * * *$ & $-0.414 * * *$ & $-0.350 * * *$ & $-0.295^{* * *}$ & $-0.226 * *$ \\
\hline ServiceWorkers & -0.14 & $-0.248^{* * *}$ & $-0.346 * * *$ & $-0.399 * * *$ & $-0.365 * * *$ & $-0.333^{* * *}$ & $-0.338 * * *$ \\
\hline SkilledAgricultur & 0.683 & $0.251^{*}$ & -0.0794 & $-0.324^{*}$ & $-0.765 *$ & $-1.182^{*}$ & -1.496 \\
\hline Craftsmen & $-1.628 * * *$ & $-1.715^{* * *}$ & $-1.244 * * *$ & $-0.684 * * *$ & $-0.557 * * *$ & $-0.555^{* * *}$ & $-0.708^{* * *}$ \\
\hline PlantOperators & -0.119 & $-0.233 * * *$ & $-0.296 * * *$ & $-0.359 * * *$ & $-0.359 * * *$ & $-0.347^{*}$ & $-0.372 *$ \\
\hline ElementaryOpera & $-0.173^{*}$ & $-0.306 * * *$ & $-0.372 * * *$ & $-0.454 * * *$ & $-0.413^{* * *}$ & $-0.428 * * *$ & $-0.336^{*}$ \\
\hline medium & $0.219 * * *$ & $0.247 * * *$ & $0.248 * * *$ & $0.237 * * *$ & $0.187 * * *$ & $0.121^{*}$ & $0.165^{*}$ \\
\hline large & $0.396 * * *$ & $0.368 * * *$ & $0.302 * * *$ & $0.282 * * *$ & $0.235^{* * *}$ & $0.256^{* * *}$ & $0.301^{* * *}$ \\
\hline fulltime & $1.633^{*}$ & $1.715^{*}$ & 0.062 & 0.1 & 0.15 & 0.13 & -0.12 \\
\hline parttime & 1.146 & 1.4 & -0.31 & 0.0475 & 0.168 & 0.144 & 0.0554 \\
\hline \multirow[t]{2}{*}{ _cons } & -0.995 & -0.707 & 1.203 & $1.421 * * *$ & $1.771^{* * *}$ & $2.231 * * *$ & $2.755^{* * *}$ \\
\hline & & & & & & & 4253 \\
\hline $\mathrm{N}$ & 4253 & & & & & & \\
\hline
\end{tabular}


Table 4a: Pooled Quantile Mincer Earnings Regressions (Across Formal-Salaried/Informal Salaried/Formal Self-employed/Informal Self-employed employment)

\begin{tabular}{|c|c|c|c|c|c|c|c|}
\hline & & & & & & & \\
\hline & 5th quantile & 10th quantile & 25th quantile & 50th quantile & 75th quantile & 90th quantile & 95th quantile \\
\hline Formal Salaried & $0.559 * * *$ & $0.429 * * *$ & $0.268 * * *$ & $0.159 * * *$ & $0.0754^{* *}$ & -0.0291 & $-0.154^{* *}$ \\
\hline Formal Self-employed & $0.490 * * *$ & $0.417 * * *$ & $0.238 * * *$ & $0.217 * * *$ & $0.240 * * *$ & $0.168 * * *$ & $0.161^{*}$ \\
\hline Informal Self-employed & $-0.318^{* * *}$ & $-0.217 * * *$ & $-0.0991 * * *$ & -0.0203 & 0.0396 & $0.0743^{*}$ & 0.0826 \\
\hline Hourspw & $-0.0158^{* * *}$ & $-0.0162 * * *$ & $-0.0164 * * *$ & $-0.0166^{* * *}$ & $-0.0170 * * *$ & $-0.0167 * * *$ & $-0.0164 * * *$ \\
\hline Exper & $0.0303^{* * * *}$ & $0.0271^{* * *}$ & $0.0252^{* * *}$ & $0.0242^{* * *}$ & $0.0246 * * *$ & $0.0177 * * *$ & $0.00946 *$ \\
\hline Expersq & $-0.000697 * * *$ & $-0.000616 * * *$ & $-0.000556 * * *$ & $-0.000517 * * *$ & $-0.000514 * * *$ & $-0.000303 * * *$ & -0.0000605 \\
\hline Female & -0.0450 & $-0.0687 * * *$ & $-0.0653^{* * *}$ & $-0.0682^{* * *}$ & $-0.0438 * *$ & -0.0423 & -0.0277 \\
\hline age25to44 & 0.0624 & 0.00428 & 0.0222 & $0.0551^{* * *}$ & $0.0613^{* *}$ & -0.0360 & $-0.0952^{*}$ \\
\hline age45to64 & 0.0657 & -0.00668 & 0.0159 & $0.0445^{*}$ & 0.0510 & -0.0307 & -0.115 \\
\hline Illiterate & $-0.279 *$ & -0.107 & $-0.104 * *$ & $-0.121 * * *$ & $-0.0974 *$ & -0.0136 & -0.0775 \\
\hline None & 0.0456 & -0.0387 & -0.0462 & -0.0333 & $-0.0811^{* * *}$ & $-0.155^{* * *}$ & $-0.167 * *$ \\
\hline Secondary & 0.0158 & $0.0386 *$ & $0.0443^{* * *}$ & $0.0714^{* * *}$ & $0.0775 * * *$ & $0.0887 * * *$ & $0.0904^{* *}$ \\
\hline High & $0.169 * * *$ & $0.156^{* * *}$ & $0.158 * * *$ & $0.188^{* * *}$ & $0.184 * * *$ & $0.205^{* * *}$ & $0.184 * * *$ \\
\hline Vocational & $0.139 * * *$ & $0.133^{* * * *}$ & $0.165^{* * *}$ & $0.195 * * *$ & $0.200^{* * *}$ & $0.205^{* * *}$ & $0.214 * * *$ \\
\hline University & $0.390 * * *$ & $0.392 * * *$ & $0.392^{* * *}$ & $0.432 * * *$ & $0.434 * * *$ & $0.451 * * *$ & $0.489 * * *$ \\
\hline student & 0.0961 & -0.235 & -0.774 & 0.109 & -0.316 & -1.036 & -1.634 \\
\hline Married & 0.0358 & $0.0594 * *$ & $0.0627^{* * *}$ & $0.0432^{* * *}$ & 0.0195 & 0.0200 & 0.0167 \\
\hline hhead & $0.154 * * *$ & $0.108^{* * *}$ & $0.0876 * * *$ & $0.0692 * * *$ & $0.103^{* * *}$ & $0.108^{* * *}$ & $0.103 * * *$ \\
\hline child & 0.0204 & $0.0320^{*}$ & $0.0201^{*}$ & $0.0277^{* *}$ & 0.0110 & 0.0249 & 0.0437 \\
\hline hhsize & -0.000952 & $-0.00809 *$ & $-0.00897 * * *$ & $-0.0113 * * *$ & $-0.00872^{* *}$ & $-0.0128 * * *$ & $-0.0161 * * *$ \\
\hline otherf & $-0.207 * * *$ & $-0.166 * * *$ & $-0.0553^{*}$ & 0.0278 & $0.0633^{*}$ & $0.122 * *$ & $0.211^{* * *}$ \\
\hline Mining & -0.0307 & -0.0444 & -0.0214 & 0.0259 & 0.117 & $0.183^{* *}$ & 0.0924 \\
\hline Energy & 0.193* & $0.199 * *$ & $0.297 * * *$ & $0.334^{* * *}$ & $0.315^{* * *}$ & $0.249 * * *$ & $0.166 * *$ \\
\hline Construction & $0.153 * * *$ & $0.146^{* * *}$ & $0.131^{* * *}$ & $0.160^{* * *}$ & $0.200^{* * *}$ & $0.167 * * *$ & $0.123 * * *$ \\
\hline Trade & $0.0877^{* * *}$ & $0.0496 *$ & 0.00483 & 0.00657 & $0.0324 *$ & $0.0459^{*}$ & 0.0278 \\
\hline Hotels & 0.0573 & 0.0464 & -0.00557 & 0.0287 & 0.0210 & 0.0365 & 0.0525 \\
\hline Transportation & $0.123 * * *$ & $0.0823^{* * *}$ & $0.0778^{* * *}$ & $0.104 * * *$ & $0.159^{* * *}$ & $0.152 * * *$ & $0.118^{* *}$ \\
\hline Finances & $-0.0850 * *$ & $-0.0773 * * *$ & $-0.112 * * *$ & $-0.0460^{*}$ & $0.0841^{* *}$ & $0.146^{* * *}$ & $0.122 * *$ \\
\hline PublicAdministration & $0.132 * * *$ & $0.124 * * *$ & $0.130^{* * *}$ & $0.113^{* * *}$ & $0.0470^{* * *}$ & -0.0407 & $-0.105^{* *}$ \\
\hline Education & $0.148 * * *$ & $0.109 * * *$ & $0.0607^{* * *}$ & -0.00216 & $-0.152 * * *$ & $-0.331 * * *$ & $-0.469 * * *$ \\
\hline Health & 0.0717 & $0.0781^{*}$ & $0.114^{* * *}$ & $0.133^{* * *}$ & $0.0898 * * *$ & 0.0492 & 0.0710 \\
\hline OtherServices & 0.0540 & 0.0225 & -0.00219 & 0.000221 & 0.0130 & -0.0315 & -0.0894 \\
\hline Legislators & $-0.312^{* * *}$ & $-0.288 * * *$ & $-0.117^{* * *}$ & 0.0309 & $0.0841^{* *}$ & $0.0835^{* *}$ & $0.110^{* *}$ \\
\hline Technicians & $-0.208^{* * *}$ & $-0.198 * * *$ & $-0.193^{* * *}$ & $-0.142 * * *$ & $-0.157^{* * *}$ & $-0.232 * * *$ & $-0.241^{* * *}$ \\
\hline Clerks & $-0.276^{* * *}$ & $-0.315^{* * *}$ & $-0.314 * * *$ & $-0.285 * * *$ & $-0.321 * * *$ & $-0.379 * * *$ & $-0.325 * * *$ \\
\hline ServiceWorkers & $-0.315^{* * *}$ & $-0.351 * * *$ & $-0.339 * * *$ & $-0.293^{* * *}$ & $-0.324 * * *$ & $-0.370 * * *$ & $-0.375^{* * *}$ \\
\hline SkilledAgricultural & -0.359 & $-0.385 * * *$ & $-0.294 * * *$ & $-0.264 * * *$ & $-0.326 * * *$ & $-0.485 * * *$ & $-0.507 * * *$ \\
\hline Craftsmen & $-0.382 * * *$ & $-0.377 * * *$ & $-0.339 * * *$ & $-0.282 * * *$ & $-0.319 * * *$ & $-0.363 * * *$ & $-0.400 * * *$ \\
\hline PlantOperators & $-0.287 * * *$ & $-0.321 * * *$ & $-0.321^{* * *}$ & $-0.270^{* * *}$ & $-0.328 * * *$ & $-0.389 * * *$ & $-0.384 * * *$ \\
\hline ElementaryOperations & $-0.390^{* * *}$ & $-0.428 * * *$ & $-0.431^{* * *}$ & $-0.387 * * *$ & $-0.416^{* * *}$ & $-0.428 * * *$ & $-0.382 * * *$ \\
\hline medium & $0.142^{* * *}$ & $0.112^{* * *}$ & $0.0940^{* * *}$ & $0.0935^{* * *}$ & $0.114 * * *$ & $0.110^{* * *}$ & $0.0965^{* * *}$ \\
\hline large & $0.300 * * *$ & $0.259 * * *$ & $0.212^{* * *}$ & $0.204^{* * *}$ & $0.249 * * *$ & $0.285^{* * *}$ & $0.278^{* * *}$ \\
\hline fulltime & 0.191 & 0.229 & 0.0596 & 0.0823 & 0.0197 & -0.257 & $-0.538 *$ \\
\hline parttime & -0.807 & $-0.374 *$ & -0.130 & $0.117^{*}$ & $0.143 *$ & -0.0478 & -0.165 \\
\hline _cons & 0.122 & $0.511^{* * *}$ & $1.001 * * *$ & $1.193^{* * *}$ & $1.587^{* * *}$ & $2.365^{* * *}$ & $2.987 * * *$ \\
\hline $\mathrm{N}$ & 23656 & & & & & & \\
\hline
\end{tabular}


Table 4b: Pooled Quantile Mincer Earnings Regressions (Across Formal-Salaried/Informal Salaried/Formal Self-employed/Informal Self-employed employment)

\begin{tabular}{|c|c|c|c|c|c|c|c|}
\hline & & & MAI & & & & \\
\hline & 5th quantile & 10th quantile & 25th quantile & 50th quantile & 75th quantile & 90th quantile & 95th quantile \\
\hline Formal Salaried & $0.446^{* * *}$ & $0.387 * * *$ & $0.232^{* * *}$ & $0.155^{* * *}$ & $0.118^{* * *}$ & 0.0156 & -0.0877 \\
\hline Formal Self-employed & $0.390 * * *$ & $0.392^{* * *}$ & $0.221^{* * *}$ & $0.217^{* * *}$ & $0.268^{* * *}$ & $0.212^{* * *}$ & $0.224 * * *$ \\
\hline Informal Self-employed & $-0.134^{* *}$ & -0.0609 & -0.00963 & 0.0154 & $0.0842^{* *}$ & $0.136^{* *}$ & $0.131^{*}$ \\
\hline Hourspw & $-0.0152^{* * *}$ & $-0.0160^{* * *}$ & $-0.0168 * * *$ & $-0.0165 * * *$ & $-0.0160 * * *$ & $-0.0161 * * *$ & $-0.0152^{* * *}$ \\
\hline Exper & $0.0293^{* * *}$ & $0.0271^{* * *}$ & $0.0259 * * *$ & $0.0253^{* * *}$ & $0.0279 * * *$ & $0.0221^{* * *}$ & $0.0173^{* * *}$ \\
\hline Expersq & $-0.000669 * * *$ & $-0.000634 * * *$ & $-0.000594 * * *$ & $-0.000532 * * *$ & $-0.000580^{* * *}$ & $-0.000401 * * *$ & -0.000225 \\
\hline age25to44 & 0.0568 & 0.023 & 0.0198 & $0.0344^{*}$ & 0.0243 & $-0.102^{* *}$ & $-0.174 * * *$ \\
\hline age45to64 & 0.0335 & 0.0106 & 0.0215 & 0.022 & 0.0196 & $-0.0969 *$ & $-0.190 * *$ \\
\hline Illiterate & $-0.210^{* *}$ & -0.086 & $-0.0809 *$ & $-0.104 * * *$ & $-0.143^{* *}$ & -0.0406 & -0.157 \\
\hline None & 0.0349 & -0.014 & $-0.0534^{*}$ & $-0.0640 *$ & $-0.0870 * *$ & $-0.146^{* *}$ & $-0.156^{*}$ \\
\hline Secondary & -0.000341 & $0.0392 *$ & $0.0505^{* * *}$ & $0.0801^{* * *}$ & $0.0828 * * *$ & $0.0862^{* *}$ & $0.0874^{* *}$ \\
\hline High & $0.171^{* * *}$ & $0.156^{* * *}$ & $0.164^{* * *}$ & $0.197^{* * *}$ & $0.193^{* * *}$ & $0.195^{* * *}$ & $0.185^{* * *}$ \\
\hline Vocational & $0.102^{* *}$ & $0.116^{* * *}$ & $0.171^{* * *}$ & $0.204 * * *$ & $0.210^{* * *}$ & $0.223 * * *$ & $0.225^{* * *}$ \\
\hline University & $0.381 * * *$ & $0.389^{* * *}$ & $0.406^{* * *}$ & $0.439 * * *$ & $0.425^{* * *}$ & $0.436^{* * *}$ & $0.503^{* * *}$ \\
\hline student & -0.0482 & -0.291 & -0.822 & 0.13 & -0.279 & -0.998 & -1.497 \\
\hline Married & $0.134^{* *}$ & $0.106^{* * *}$ & $0.0630^{* * *}$ & $0.0524^{* * *}$ & 0.0128 & 0.0485 & 0.0143 \\
\hline hhead & $0.0898^{* *}$ & $0.0684^{* * *}$ & $0.0944 * * *$ & $0.0693 * * *$ & $0.110 * * *$ & $0.0941^{* *}$ & $0.0833^{* *}$ \\
\hline child & $0.0633^{*}$ & $0.0375^{*}$ & 0.0158 & $0.0316^{* *}$ & -0.0029 & 0.0000247 & 0.0274 \\
\hline hhsize & -0.00791 & $-0.00820 *$ & $-0.00600^{* *}$ & $-0.00962 * * *$ & -0.00528 & $-0.0120^{* *}$ & $-0.0132 *$ \\
\hline otherf & $-0.117 *$ & $-0.124 * *$ & -0.00914 & $0.0376^{*}$ & 0.0419 & $0.127^{* *}$ & $0.193^{* * *}$ \\
\hline Mining & -0.0715 & -0.0354 & -0.0467 & 0.0147 & 0.0963 & $0.176^{* * *}$ & 0.0921 \\
\hline Energy & $0.188^{*}$ & $0.224^{* *}$ & $0.283^{* * *}$ & $0.371^{* * *}$ & $0.292 * * *$ & $0.214^{* * *}$ & $0.211^{* * *}$ \\
\hline Construction & 0.0458 & $0.0906^{* * *}$ & $0.101^{* * *}$ & $0.138^{* * *}$ & $0.183^{* * *}$ & $0.165^{* * *}$ & $0.161^{* * *}$ \\
\hline Trade & 0.0205 & -0.0089 & $-0.0259 *$ & -0.0103 & 0.0115 & 0.0391 & 0.0426 \\
\hline Hotels & 0.0207 & -0.01 & -0.043 & -0.00272 & -0.0138 & 0.0121 & 0.0504 \\
\hline Transportation & $0.0727 *$ & $0.0454^{*}$ & $0.0459 * * *$ & $0.0771^{* * *}$ & $0.128^{* * *}$ & $0.161^{* * *}$ & $0.141^{* * *}$ \\
\hline Finances & $-0.136^{* *}$ & $-0.139 * * *$ & $-0.148 * * *$ & $-0.0889 * * *$ & 0.0662 & $0.159^{* * *}$ & $0.159^{* * *}$ \\
\hline PublicAdministration & $0.0844^{*}$ & $0.0918^{* * *}$ & $0.112^{* * *}$ & $0.0975^{* * *}$ & 0.0366 & -0.0454 & $-0.0675^{*}$ \\
\hline Education & $0.0983 *$ & $0.0811^{* * *}$ & $0.0415^{*}$ & -0.0155 & $-0.152^{* * *}$ & $-0.328 * * *$ & $-0.407 * * *$ \\
\hline Health & 0.0235 & 0.0219 & $0.136^{* * *}$ & $0.153^{* * *}$ & $0.114^{* *}$ & 0.0656 & 0.12 \\
\hline OtherServices & -0.077 & $-0.0699 *$ & $-0.0631^{* *}$ & $-0.0514 *$ & -0.0364 & $-0.0774 *$ & -0.0863 \\
\hline Legislators & $-0.382 * * *$ & $-0.352 * * *$ & $-0.156 * * *$ & 0.0238 & $0.0653^{*}$ & 0.0465 & $0.134^{*}$ \\
\hline Technicians & $-0.298 * * *$ & $-0.228 * * *$ & $-0.188 * * *$ & $-0.129 * * *$ & $-0.127 * * *$ & $-0.217^{* * * *}$ & $-0.174 * *$ \\
\hline Clerks & $-0.328^{* * *}$ & $-0.326 * * *$ & $-0.295 * * *$ & $-0.268 * * *$ & $-0.309 * * *$ & $-0.413^{* * *}$ & $-0.348 * * *$ \\
\hline ServiceWorkers & $-0.376^{* * *}$ & $-0.364 * * *$ & $-0.326 * * *$ & $-0.277^{* * *}$ & $-0.301^{* * *}$ & $-0.384 * * *$ & $-0.369^{* * *}$ \\
\hline SkilledAgricultural & -0.368 & $-0.439 *$ & $-0.328 * * *$ & $-0.243^{* * *}$ & $-0.306 * * *$ & $-0.472 * * *$ & $-0.513 * * * *$ \\
\hline Craftsmen & $-0.360^{* * *}$ & $-0.355 * * *$ & $-0.313^{* * *}$ & $-0.259 * * *$ & $-0.293 * * *$ & $-0.365 * * *$ & $-0.354 * * *$ \\
\hline PlantOperators & $-0.355^{* * *}$ & $-0.356 * * *$ & $-0.316^{* * *}$ & $-0.271^{* * *}$ & $-0.307 * * *$ & $-0.411^{* * *}$ & $-0.373^{* * *}$ \\
\hline ElementaryOperations & $-0.470^{* * *}$ & $-0.460 * * *$ & $-0.441^{* * *}$ & $-0.387 * * *$ & $-0.407 * * *$ & $-0.440^{* * *}$ & $-0.373^{* * *}$ \\
\hline medium & $0.142^{* * *}$ & $0.101^{* * *}$ & $0.0753 * * *$ & $0.0768^{* * *}$ & $0.0957^{* * *}$ & $0.103^{* * *}$ & $0.0959 * * *$ \\
\hline large & $0.277^{* * *}$ & $0.240^{* * *}$ & $0.193^{* * *}$ & $0.204^{* * *}$ & $0.249 * * *$ & $0.291 * * *$ & $0.287 * * *$ \\
\hline fulltime & 0.0322 & 0.113 & -0.00472 & 0.0629 & -0.0292 & -0.286 & -0.433 \\
\hline parttime & 0.0345 & 0.0527 & -0.0485 & 0.151 & 0.118 & -0.0899 & -0.021 \\
\hline _cons & $0.340^{*}$ & $0.645^{* * *}$ & $1.075^{* * *}$ & $1.192 * * *$ & $1.564 * * *$ & $2.360 * * *$ & $2.743^{* * *}$ \\
\hline $\mathrm{N}$ & 19403 & & & & & & 19403 \\
\hline
\end{tabular}


Table 4c: Pooled Quantile Mincer Earnings Regressions (Across Formal-Salaried/Informal Salaried/Formal Self-employed/Informal Self-employed employment)

\begin{tabular}{|c|c|c|c|c|c|c|c|}
\hline & & & FEM & & & & \\
\hline & 5th quantile & 10th quantile & 25th quantile & 50th quantile & 75th quantile & 90th quantile & 95th quantile \\
\hline Formal Salaried & $0.481^{* * *}$ & $0.401^{* * *}$ & $0.308^{* * *}$ & $0.150^{* * *}$ & -0.00263 & -0.200 & $-0.421 * * *$ \\
\hline Formal Self-employed & 0.0466 & 0.255 & 0.121 & $0.286^{* *}$ & $0.195 *$ & -0.0441 & $-0.372 *$ \\
\hline Informal Self-employed & $-0.670^{* *}$ & $-0.455^{*}$ & $-0.618^{* * *}$ & $-0.400^{* * *}$ & $-0.267^{* * *}$ & $-0.275^{* *}$ & -0.288 \\
\hline Hourspw & $-0.0188^{* * *}$ & $-0.0178 * * *$ & $-0.0188^{* * * *}$ & $-0.0184^{* * * *}$ & $-0.0216^{* * *}$ & $-0.0243^{* * *}$ & $-0.0224 * * *$ \\
\hline Exper & $0.0412^{* * *}$ & $0.0262^{* * *}$ & $0.0236^{* * *}$ & $0.0181^{* * *}$ & $0.0152^{* * *}$ & 0.00506 & -0.0147 \\
\hline Expersq & $-0.000916^{*}$ & -0.000441 & $-0.000547 * * *$ & $-0.000355 * * *$ & -0.000306 & -0.0000443 & 0.000447 \\
\hline age25to44 & 0.0447 & 0.0689 & $0.0716^{* *}$ & $0.0908^{* *}$ & $0.0919 * *$ & $0.111^{*}$ & 0.157 \\
\hline age45to64 & -0.0456 & -0.00792 & 0.0672 & 0.0478 & 0.0856 & 0.0994 & 0.191 \\
\hline Illiterate & 0.0108 & -0.129 & -0.107 & -0.0308 & -0.0222 & 0.120 & 0.179 \\
\hline None & -0.109 & -0.0676 & 0.103 & 0.0528 & 0.0481 & -0.206 & -0.404 \\
\hline Secondary & 0.0844 & $0.0945^{*}$ & 0.0435 & $0.0819^{*}$ & 0.0717 & 0.0688 & -0.000825 \\
\hline High & $0.246^{* * *}$ & $0.203^{* * *}$ & $0.170^{* * *}$ & $0.189^{* * *}$ & $0.256^{* * *}$ & $0.365^{* * *}$ & $0.275^{* *}$ \\
\hline Vocational & $0.229 * * *$ & $0.189 * * *$ & $0.188^{* * *}$ & $0.167 * * *$ & $0.205^{* * *}$ & $0.294 * * *$ & 0.137 \\
\hline University & $0.415^{* * *}$ & $0.377^{* * *}$ & $0.348^{* * *}$ & $0.363^{* * *}$ & $0.484^{* * *}$ & $0.573^{* * *}$ & $0.469 * * *$ \\
\hline Married & -0.00984 & 0.0248 & $0.0558^{*}$ & 0.0134 & -0.0269 & -0.0219 & -0.0461 \\
\hline hhead & 0.0969 & $0.0978^{* * *}$ & $0.0749 * *$ & 0.0503 & 0.0643 & $0.138^{* * *}$ & 0.133 \\
\hline child & 0.0178 & 0.0169 & 0.0275 & 0.0167 & 0.0352 & $0.0985^{* *}$ & $0.199 * * *$ \\
\hline hhsize & -0.0193 & $-0.0247 *$ & -0.0129 & $-0.0197^{* *}$ & $-0.0247 * *$ & -0.0188 & $-0.0536^{* * *}$ \\
\hline otherf & -0.0929 & -0.101 & -0.103 & 0.00147 & 0.0691 & -0.00968 & 0.163 \\
\hline Mining & 0.532 & 0.408 & 0.156 & -0.0000299 & 0.0189 & -0.338 & $-0.732^{*}$ \\
\hline Energy & -3.246 & -3.364 & 0.0486 & -0.0933 & -0.200 & $-0.508^{* *}$ & $-0.917 * * *$ \\
\hline Construction & $0.299 *$ & 0.144 & 0.0465 & 0.0406 & 0.0386 & 0.277 & -0.149 \\
\hline Trade & 0.0683 & 0.0688 & $0.113^{* * *}$ & 0.0449 & 0.0341 & 0.0442 & -0.0722 \\
\hline Hotels & 0.00923 & -0.0537 & 0.0757 & $0.163^{* *}$ & $0.131^{*}$ & 0.179 & 0.406 \\
\hline Transportation & $0.310^{* *}$ & $0.217^{* * *}$ & $0.196^{* *}$ & $0.273^{* * *}$ & $0.243^{* * *}$ & -0.0217 & $-0.213^{*}$ \\
\hline Finances & 0.00536 & -0.0129 & 0.0173 & 0.0533 & 0.0579 & -0.0182 & -0.138 \\
\hline PublicAdministration & 0.200 & $0.144 *$ & $0.163^{* * *}$ & $0.154^{* *}$ & 0.0691 & -0.152 & $-0.347^{* *}$ \\
\hline Education & 0.0968 & 0.0782 & 0.0305 & -0.0286 & $-0.203 * * *$ & $-0.451^{* * *}$ & $-0.691^{* * *}$ \\
\hline Health & 0.108 & 0.0813 & $0.107^{* *}$ & $0.103^{*}$ & 0.0857 & 0.000245 & -0.190 \\
\hline OtherServices & 0.148 & 0.120 & $0.139 * *$ & $0.157^{* *}$ & $0.115^{*}$ & -0.0885 & $-0.354 * * *$ \\
\hline Legislators & -0.0516 & -0.0691 & 0.0338 & $0.138^{*}$ & $0.287^{* * *}$ & $0.374^{* * *}$ & 0.223 \\
\hline Technicians & -0.138 & $-0.169 * *$ & $-0.208^{* * *}$ & $-0.221 * * *$ & $-0.193^{* * *}$ & $-0.281^{* * *}$ & $-0.277^{* * *}$ \\
\hline Clerks & $-0.255^{* * *}$ & $-0.334 * * *$ & $-0.408 * * *$ & $-0.404 * * *$ & $-0.346^{* * *}$ & $-0.288 * * *$ & $-0.262 * *$ \\
\hline ServiceWorkers & $-0.183^{*}$ & $-0.272 * * *$ & $-0.403 * * *$ & $-0.402 * * *$ & $-0.352^{* * *}$ & $-0.334 * * *$ & $-0.361 * *$ \\
\hline SkilledAgricultural & $1.145^{*}$ & 0.557 & $0.446 *$ & -0.0682 & -0.469 & -0.962 & $-1.366^{*}$ \\
\hline Craftsmen & $-1.356^{* * *}$ & $-1.517 * * *$ & $-1.093 * * *$ & $-0.640^{* * *}$ & $-0.562^{* * *}$ & $-0.539^{* * *}$ & $-0.713^{* * *}$ \\
\hline PlantOperators & -0.171 & $-0.254^{* * *}$ & $-0.345^{* * *}$ & $-0.360 * * *$ & $-0.354^{* * *}$ & $-0.331 *$ & $-0.363^{*}$ \\
\hline ElementaryOperations & $-0.232 *$ & $-0.309 * * *$ & $-0.427 * * *$ & $-0.468 * * *$ & $-0.399 * * *$ & $-0.402^{* * *}$ & $-0.409 * *$ \\
\hline medium & $0.184^{* *}$ & $0.230 * * *$ & $0.213^{* * *}$ & $0.224 * * *$ & $0.192 * * *$ & $0.142^{* *}$ & $0.171^{*}$ \\
\hline large & $0.354^{* * *}$ & $0.356^{* * *}$ & $0.268^{* * *}$ & $0.270^{* * *}$ & $0.243^{* * *}$ & $0.282^{* * *}$ & $0.285^{* * *}$ \\
\hline fulltime & $1.605^{*}$ & $1.590^{*}$ & 0.174 & 0.0974 & 0.154 & 0.247 & -0.0386 \\
\hline parttime & 1.177 & 1.277 & -0.115 & 0.0557 & 0.179 & 0.256 & 0.137 \\
\hline _cons & -1.262 & -0.937 & 0.919 & $1.319 * * *$ & $1.766^{* * *}$ & $2.341 * * *$ & $3.222 * * *$ \\
\hline
\end{tabular}


Table 5a: Fixed Effects Regressions (Across Formal/Informal Employment)

\begin{tabular}{|c|c|c|c|}
\hline & $\begin{array}{c}\text { ALL } \\
(1) \\
\text { Fixed Effects }\end{array}$ & $\begin{array}{c}\text { M ALE } \\
\text { (2) } \\
\text { Fixed Effects }\end{array}$ & $\begin{array}{c}\text { FEM ALE } \\
(3) \\
\text { Fixed Effects }\end{array}$ \\
\hline Informal & -0.0697 & $-0.106^{*}$ & 0.0741 \\
\hline Hourspw & $-0.0179 * * *$ & $-0.0177 * * *$ & $-0.0193^{* * *}$ \\
\hline Exper & 0.00700 & 0.00903* & -0.000942 \\
\hline Expersq & -0.000141 & -0.000187 & 0.000117 \\
\hline Female & 0 & & \\
\hline age25to44 & $0.0776^{* *}$ & $0.0951^{* *}$ & 0.0188 \\
\hline age45to64 & $0.0944^{*}$ & $0.109 * *$ & 0.0760 \\
\hline Illiterate & 0.0262 & 0.0430 & $-0.259 * *$ \\
\hline None & -0.117 & -0.123 & 0.185 \\
\hline Secondary & -0.0168 & -0.0670 & 0.321 \\
\hline High & 0.0977 & 0.0388 & $0.377^{*}$ \\
\hline Vocational & $0.284 *$ & 0.208 & $0.650 * *$ \\
\hline University & 0.237 & 0.241 & $0.433^{*}$ \\
\hline student & 0.251 & 0.289 & 0 \\
\hline Married & 0.0361 & 0.0460 & 0.00557 \\
\hline hhead & 0.0104 & -0.00743 & 0.0609 \\
\hline child & 0.00971 & -0.0130 & 0.103 \\
\hline hhsize & -0.00296 & 0.00146 & $-0.0364 *$ \\
\hline otherf & -0.0211 & -0.0424 & 0.0146 \\
\hline Mining & 0.172 & 0.157 & 0 \\
\hline Energy & 0.0411 & 0.123 & -0.710 \\
\hline Construction & 0.0647 & 0.0493 & 0.204 \\
\hline Trade & 0.0272 & 0.00604 & 0.176 \\
\hline Hotels & 0.0809 & 0.0569 & 0.263 \\
\hline Transportation & -0.0319 & -0.0457 & 0.146 \\
\hline Finances & -0.00813 & -0.0663 & 0.251 \\
\hline PublicAdministration & -0.00110 & 0.0182 & 0.0182 \\
\hline Education & -0.0616 & 0.0897 & -0.140 \\
\hline Health & 0.160 & 0.215 & 0.212 \\
\hline OtherServices & 0.0865 & 0.0563 & 0.196 \\
\hline Legislators & 0.0847 & 0.0396 & 0.116 \\
\hline Technicians & -0.151 & $-0.214^{*}$ & -0.00883 \\
\hline Clerks & -0.0900 & -0.111 & -0.0308 \\
\hline ServiceWorkers & -0.0418 & -0.111 & 0.204 \\
\hline SkilledAgricultural & 0.0518 & -0.00960 & 0 \\
\hline Craftsmen & 0.000433 & -0.0593 & 0.215 \\
\hline PlantOperators & -0.0449 & -0.115 & 0.252 \\
\hline ElementaryOperations & -0.00381 & -0.0565 & 0.185 \\
\hline medium & -0.0149 & -0.0257 & 0.0291 \\
\hline large & $0.142 * * *$ & $0.145^{* *}$ & 0.128 \\
\hline fulltime & -0.0442 & -0.0514 & -0.00907 \\
\hline parttime & 0.0666 & 0.0844 & 0.0289 \\
\hline _cons & $1.598 * * *$ & $1.696^{* * *}$ & $1.221^{* *}$ \\
\hline $\mathrm{N}$ & 23656 & 19403 & 4253 \\
\hline
\end{tabular}


Table 5b: Fixed Effects Regressions (Across Formal-Salaried/Informal Salaried/Formal Self-employed/Informal Self-employed employment)

\begin{tabular}{|c|c|c|c|}
\hline (3) & $\begin{array}{c}\text { ALL } \\
\text { (1) } \\
\text { Fixed Effects }\end{array}$ & $\begin{array}{c}\text { MALE } \\
(2) \\
\text { Fixed Effects }\end{array}$ & $\begin{array}{c}\text { FEM ALE } \\
\text { (3) } \\
\text { Fixed Effects }\end{array}$ \\
\hline Formal salaried & 0.0518 & $0.0952 *$ & -0.0951 \\
\hline Formal self-employed & $0.156^{*}$ & $0.211^{* *}$ & -0.183 \\
\hline Informal self-employed & 0.00756 & 0.0608 & $-0.402^{*}$ \\
\hline Hourspw & $-0.0180 * * *$ & $-0.0178 * * *$ & $-0.0198 * * *$ \\
\hline Exper & 0.00711 & $0.00897^{*}$ & -0.0000678 \\
\hline Expersq & -0.000143 & -0.000185 & 0.000118 \\
\hline Female & 0 & & \\
\hline age25to44 & $0.0780 * *$ & $0.0946 * *$ & 0.0179 \\
\hline age45to64 & $0.0933 *$ & $0.107 *$ & 0.0567 \\
\hline Illiterate & 0.0249 & 0.0374 & $-0.239 * *$ \\
\hline None & -0.118 & -0.121 & 0.182 \\
\hline Secondary & -0.0176 & -0.0670 & 0.309 \\
\hline High & 0.0974 & 0.0386 & $0.374^{*}$ \\
\hline Vocational & $0.282 *$ & 0.203 & $0.659 * *$ \\
\hline University & 0.236 & 0.237 & $0.447^{*}$ \\
\hline student & 0.248 & 0.287 & 0 \\
\hline Married & 0.0361 & 0.0459 & 0.00780 \\
\hline hhead & 0.0113 & -0.00653 & 0.0667 \\
\hline child & 0.00979 & -0.0123 & 0.105 \\
\hline hhsize & -0.00273 & 0.00175 & $-0.0411^{*}$ \\
\hline otherf & -0.0230 & -0.0432 & 0.00521 \\
\hline Mining & 0.172 & 0.154 & 0 \\
\hline Energy & 0.0457 & 0.128 & -0.721 \\
\hline Construction & 0.0653 & 0.0523 & 0.188 \\
\hline Trade & 0.0230 & -0.00321 & 0.156 \\
\hline Hotels & 0.0762 & 0.0538 & 0.216 \\
\hline Transportation & -0.0354 & -0.0511 & 0.135 \\
\hline Finances & -0.00949 & -0.0699 & 0.226 \\
\hline PublicAdministration & 0.00150 & 0.0216 & -0.00230 \\
\hline Education & -0.0582 & 0.0961 & -0.169 \\
\hline Health & 0.160 & 0.214 & 0.194 \\
\hline OtherServices & 0.0860 & 0.0530 & 0.184 \\
\hline Legislators & 0.0771 & 0.0239 & 0.115 \\
\hline Technicians & -0.147 & $-0.209 *$ & -0.00656 \\
\hline Clerks & -0.0859 & -0.105 & -0.0336 \\
\hline ServiceWorkers & -0.0356 & -0.0997 & 0.200 \\
\hline SkilledAgricultural & 0.0524 & -0.00405 & 0 \\
\hline Craftsmen & 0.000725 & -0.0570 & 0.212 \\
\hline PlantOperators & -0.0417 & -0.109 & 0.251 \\
\hline ElementaryOperations & -0.00130 & -0.0520 & 0.194 \\
\hline medium & -0.00564 & -0.0121 & 0.0188 \\
\hline large & $0.153 * * *$ & $0.159 * * *$ & 0.116 \\
\hline fulltime & -0.0436 & -0.0479 & -0.0382 \\
\hline parttime & 0.0633 & 0.0828 & 0.0197 \\
\hline _cons & $1.530 * * *$ & $1.578 * * *$ & $1.423 * * *$ \\
\hline $\mathrm{N}$ & 23656 & 19403 & 4253 \\
\hline
\end{tabular}


Table A1: List of Definitions

\begin{tabular}{|c|c|}
\hline Variable Name & Definition \\
\hline \multicolumn{2}{|l|}{ Formality Status } \\
\hline Formal & 1 if registered to the Social Security Institution; 0 otherwise \\
\hline Informal & 1 if not registered to the Social Security Institution; 0 otherwise \\
\hline Formal-salaried & 1 if employee working for a wage/salary and registered to the SSI; 0 otherwise \\
\hline Informal-salaried & 1 if employee working for a wage/salary and not registered to the SSI; 0 otherwise \\
\hline Formal self-employed & 1 if own-account worker and registered to the SSI; 0 otherwise \\
\hline Informal self-employed & 1 if own-account worker and not registered to the SSI; 0 otherwise \\
\hline logwagem & $\begin{array}{l}\text { Real hourly logged wages calculated using a wage-worker's income, hours worked in the main job, the Turkish Consumer Price Index or } \\
\text { Real hourly logged wages calculated using a self-employed's earnings, hours worked in the main job, the Turkish Consumer Price Index }\end{array}$ \\
\hline Hourspw & Weekly hours worked in the main job \\
\hline \multicolumn{2}{|l|}{ Individual Characteristics } \\
\hline Male & 1 if male; 0 otherwise \\
\hline Female & 1 if female; 0 otherwise \\
\hline Age15to24 & 1 if in age range; 0 otherwise \\
\hline Age25to44 & 1 if in age range; 0 otherwise \\
\hline Age45to64 & 1 if in age range; 0 otherwise \\
\hline exper & total number of years the individual has worked for since he/she first started working \\
\hline Illiterate & 1 if illiterate; 0 otherwise \\
\hline None & 1 if did not attend school; 0 otherwise \\
\hline Primary & 1 if completed primary school; 0 otherwise \\
\hline Secondary & 1 if completed secondary school; 0 otherwise \\
\hline High & 1 if completed high school; 0 otherwise \\
\hline Vocational & 1 if completed vocational school; 0 otherwise \\
\hline University & 1 if completed university; 0 otherwise \\
\hline student & 1 if currently enrolled as a student; 0 otherwise \\
\hline \multicolumn{2}{|l|}{ Household Characteristics } \\
\hline Single & 1 if not married; 0 otherwise \\
\hline Married & 1 if married; 0 otherwise \\
\hline nochild & 1 if the household do not have any children; 0 otherwise \\
\hline child & 1 if the household has children; 0 otherwise \\
\hline hhead & 1 if head of the household; 0 otherwise \\
\hline hhsize & total number of members in the household \\
\hline otherf & 1 if there is another formally employed household member; 0 otherwise \\
\hline \multicolumn{2}{|c|}{ Employment/Job Characteristics } \\
\hline Regular employee & 1 if employeed as a regular employee; 0 otherwise \\
\hline Casual employee & 1 if employed as a casual employee; 0 otherwise \\
\hline Employer & 1 if employer; 0 otherwise \\
\hline Own-account worker & 1 if own-account worker; 0 otherwise \\
\hline Unpaid Family worker & 1 if unpaid family worker; 0 otherwise \\
\hline Agriculture & 1 if employed in agriculture; 0 otherwise \\
\hline Mining & 1 if employed in mining; 0 otherwise \\
\hline Manufacturing & 1 if employed in manufacturing; 0 otherwise \\
\hline Energy & 1 if employed in energy; 0 otherwise \\
\hline Construction & 1 if employed in construction; 0 otherwise \\
\hline Trade & 1 if employed in trade; 0 otherwise \\
\hline Hotels & 1 if employed in hotels; 0 otherwise \\
\hline Transportation & 1 if employed in transportation; 0 otherwise \\
\hline Finances & 1 if employed in finances; 0 otherwise \\
\hline Public Administration & 1 if employed in piblic administration; 0 otherwise \\
\hline Education & 1 if employed in education; 0 otherwise \\
\hline Health & 1 if employed in health; 0 otherwise \\
\hline Other & 1 if employed in other services; 0 otherwise \\
\hline Legislators & 1 if employed as a legislator; 0 otherwise \\
\hline Professional & 1 if employed as a professional; 0 otherwise \\
\hline Technicals & 1 if employed as a technician; 0 otherwise \\
\hline Clerks & 1 if employed as a clerk; 0 otherwise \\
\hline Service workers & 1 if employed as a service worker; 0 otherwise \\
\hline Skilled agricultural workers & 1 if employed as a skilled agricultural worker; 0 otherwise \\
\hline Craftsmen & 1 if employed as a craftsmen; 0 otherwise \\
\hline Plant operators & 1 if employed as a plant operator; 0 otherwise \\
\hline Elementary operations & 1 if employed as a elemenatry opr. worker; 0 otherwise \\
\hline small & 1 if firm size is between 1 to $10 ; 0$ otherwise \\
\hline medium & 1 if firm size is between 11 to 49 ; 0 otherwise \\
\hline large & 1 if firm size is 50 or more; 0 otherwise \\
\hline full-time & 1 if emplyed as full-time; 0 otherwise \\
\hline part-time & 1 if employed as part-time; 0 otherwise \\
\hline
\end{tabular}

